\title{
Memories of the Photochemical: Examining the Digital Recreation of Analog Film Styles in Recent Popular Film
}

\author{
by \\ Emily Gleeson
}

A thesis submitted to the Faculty of Graduate and Postdoctoral Affairs in partial fulfillment of the requirements for the degree of

Master of Arts

in

Film Studies

Carleton University

Ottawa, Ontario

(C) 2015 Emily Gleeson 


\begin{abstract}
This thesis examines the use of the digital intermediate to recreate the appearance of analog film techniques in recent popular cinema. This particular use of the digital intermediate, which rose to prominence with various concerns about the state of cinema in the digital age, reflects an anxiety toward new technology, as well as a nostalgia for analog filmmaking techniques. The films discussed in this thesis use the digital intermediate in ways that explore themes related to nostalgia and memory. The way filmmakers use this technology reflects the various changes in digital technology and attitudes toward recent technological change in cinema.
\end{abstract}


Table of Contents

$\begin{array}{ll}\text { Introduction } & 1\end{array}$

$\begin{array}{lr}\text { Chapter One: Pleasantville } & 11\end{array}$

$\begin{array}{ll}\text { Chapter Two: The Aviator } & 34\end{array}$

$\begin{array}{ll}\text { Chapter Three: } \text { The Artist } & 53\end{array}$

$\begin{array}{ll}\text { Thesis Conclusion } & 76\end{array}$

$\begin{array}{ll}\text { References } & 79\end{array}$ 


\section{Introduction}

As digital cinema and digital production techniques have become commonplace, theorists have crafted one of three basic responses, approaching these new technologies with skepticism, neutrally, or positively. Scholars such as Paolo Cherchi Usai and Anne Friedberg have chosen to regard digital cinema with skepticism. They condemn new technological advances that they believe will eradicate celluloid and permanently change the way spectators interact with cinema. Friedberg argues that the rise of digital cinema means "the differences between the media of movies, television, and computers are rapidly diminishing,"1 and demonstrates this using the recent reissue of Metropolis (Fritz Lang, 1927):

Digital imaging, delivery, and display effectively erase the "messages" implicit in the source "medium." The digitized Metropolis illustrates how almost all of our assumptions about the cinema have changed: its image is digital, not photographically based, its screen format is small and not projection-based, its implied interactivity turns the spectator into a "user."2

The digitization of cinema, particularly film archives, also concerns Cherchi Usai. He argues that all moving images are subject to decay ${ }^{3}$, even digital images, though the causes of their deterioration are much different. ${ }^{4}$ Though he notes that the decay of cinema is "a process that can be contained or decelerated but not altogether avoided"5, much of his writing fixates on the concept of the "Model Image", which is an image viewed with no damage to the filmstrip,

\footnotetext{
${ }^{1}$ Anne Friedberg, "The End of Cinema: Multimedia and Technological Change," in The Film Theory Reader: Debates and Arguments, ed. Marc Furstenau (London and New York: Routledge, 2010), 270.

${ }^{2}$ ibid 271

${ }^{3}$ Paolo Cherchi Usai, The Death of Cinema (London: The British Film Institute, 2001), 41

${ }^{4}$ ibid 13

${ }^{5}$ ibid 17
} 
without distraction, and with viewing every image from the film without blinking or looking away from the screen. ${ }^{6}$ Cherchi Usai privileges photochemical cinema over other formats, dismissing non-celluloid cinema as a "novelty" and merely indicative of changing the rate of the loss of the model image. ${ }^{7}$

Other writers, such as John Belton, take a neutral position in the digital-versus-celluloid debate. Belton, like Cherchi Usai, is concerned with the many issues associated with archiving digital images:

At the moment, polyester safety film is the ideal medium for long-term storage of motion picture images and sound tracks. Its longevity is estimated at about one hundred years - longer if it is placed in cold storage facilities. Digital data has been stored, for the most part, on magnetic tape or disc - a format that has an effective media life of five to ten years and an estimated time until obsolescence of only five years....Films made digitally could be stored in that format, but they would have to be converted into a new format every five years. It would make more sense for them to be transferred to celluloid and stored as films. Given the rapid obsolescence of various past digital formats, it is not clear that digital information can be retrieved in the future. ${ }^{8}$

Though Belton recognizes the issues with compatibility, obsolescence, and decay that digital archivists must handle, he also understands the creative possibilities associated with digital filmmaking techniques. When using the digital intermediate, Belton notes that artists "can isolate individual elements of the image and manipulate them without changing anything else, enabling filmmakers to change the saturation of one particular color of one particular object in a shot, to

\footnotetext{
${ }^{6}$ ibid 49

7 ibid 87

${ }^{8}$ John Belton, "Digital Cinema: A False Revolution," in The Film Theory Reader: Debates and Arguments, ed. Marc Furstenau (London and New York: Routledge, 2010), 292.
} 
control the brightness of light coming through a window, to tinker with general atmosphere, or to alter skin tone." $" 9$

Stephen Prince, on the other hand, has a very positive attitude toward digital cinema, particularly digital visual effects. He notes that digital cinema "challenges us to think anew about the nature of realism in cinema"10 and that digital effects and techniques are "merely the latest instance in a long history of imaging technologies that have been designed to take viewers through a looking glass into domains of novel perceptual experience." ${ }^{11} \mathrm{He}$ also criticizes other writers for writing about the digital transition with "an anxious tone, posing crises of form and function and meaning," 12 as he prefers to focus on how digital tools have allowed filmmakers to improve on techniques from the analog era. ${ }^{13}$

The positions of these various writers toward the rise of digital cinema present an unease with digital cinema; all are concerned with how the digital revolution will affect the future of cinema. However, many writers do not thoroughly examine how this unease with digital cinema currently affects filmmakers and audience members. As Prince notes, many spectators believe that digital visual effects "call to mind gaudy spectacle, overstuffed blockbusters, or action adventure fantasies catering to young audiences," 14 while filmmakers have embraced the digital intermediate and other techniques to create "invisible digital effects," allowing them to correct

\footnotetext{
${ }^{9}$ John Belton, "Painting by Numbers: The Digital Intermediate," Film Quarterly 61.3 (2008): 59.

${ }^{10}$ Stephen Prince, Digital Visual Effects in Cinema: The Seduction of Reality (New Brunswick, New Jersey: Rutgers University Press, 2012), 11.

${ }^{11}$ ibid 11

${ }^{12}$ ibid 4

${ }^{13}$ ibid 4-5

${ }^{14}$ ibid 1
} 
colour or lighting in scenes. ${ }^{15}$ As the former perception of digital visual effects is more prevalent, many filmmakers and writers criticize the use of digital effects to achieve a celluloid aesthetic:

Criticism of digital imaging on the basis that it strives for photorealism overlooks a prime motivation on the part of effects artists when they do seek a photo-real appearance. Such an appearance minimizes the artificiality of computer-generated imagery, and it creates continuity with the historical traditions of cinematic imaging that are photographic....These [photorealistic effects] serve to soften the tendency for computer images to look overly calculated and excessively designed, cold, and hard. ${ }^{16}$

As Prince mentions, photorealistic digital effects have many purposes, which are interesting to examine in relation to the unease with digital cinema. As digital special effects, digital projection, and digital distribution of cinema have become more widespread, many recent popular films have used a variety of digital visual effects to emulate past cinematic styles. These recreated cinematic styles vary, and include black-and-white, two- and three-strip Technicolor, and even simply reproduction of film grain on digital images. This reproduction can be considered a form of "techno-nostalgia," 17 and many of the films that recreate these various aesthetics are set in past eras. Thus, filmmakers using these techniques are attempting to evoke a certain aesthetic or atmosphere associated with the era in which the film is set, as well as inviting spectators to engage in a reminiscence or nostalgia for this past era.

Therefore, this thesis will examine the use of the digital intermediate and other digital filmmaking techniques to recreate film styles from previous decades that were previously exclusive to photochemical cinema. It should also be noted that this thesis will not necessarily take a specific skeptical, neutral, or positive position on the debates surrounding digital cinema.

\footnotetext{
${ }^{15}$ ibid 77

16 ibid 95

${ }^{17}$ ibid 4
} 
Instead, the focus of this thesis will consider how, at this stage of film digitization, the new technology is being used in a "nostalgic" manner to reproduce film styles from previous eras. ${ }^{18}$ There is a clear tension between honouring cinema's celluloid past and embracing the future of digital techniques, which is clearly seen as filmmakers use digital tools to recreate older film styles. To investigate this tension, both theory concerning digital cinema and writing focusing on the concept of nostalgia will be used. This allows for an examination of the two main issues that surround this interesting tension: filmmakers' apprehensiveness toward digital cinema, and a recent interest in nostalgia seen throughout popular culture. The three films that will be analyzed in this thesis represent a different mode of the nostalgic response to digitization, providing an opportunity for an in-depth analysis of negative concerns regarding digital cinema.

To narrow the scope of my argument, not all digital cinematic techniques will be discussed; the primary focus will be placed on the digital intermediate. The three films analyzed in this thesis use the digital intermediate, either alone or in combination with other digital filmmaking techniques, to recreate filmmaking styles that were previously exclusively associated with photochemical material. Thus, a brief overview of the digital intermediate is necessary. John Belton provides a good, basic definition of the process: “'Digital Intermediate'...is a term that refers to the intermediate stage of post-production between the initial digitization of original film material and final transfer of those digital files back to film.”19

\footnotetext{
${ }^{18}$ While this thesis focuses on filmmakers using digital effects to recreate analog film styles, it should be noted that some filmmakers are not responding to the digitization of cinema in a nostalgic manner. These filmmakers use digital effects to push the limits of current technologies and are looking for new visual possibilities. Birdman (Or, The Unexpected Virtue of Ignorance) (Alejandro González Iñárritu, 2014) and Gravity (Alfonso Cuarón, 2013) are two such examples. However, both films also exhibit a certain anxiety about digitization; Birdman is anxious about cinema as an art form, particularly in comparison to theatre; and Gravity betrays an anxiety regarding the use of digital effects for spectacle.

${ }^{19}$ ibid 58
} 
When using the digital intermediate, an original celluloid negative is digitally scanned and converted into a data file, ${ }^{20}$ allowing an opportunity for greater control over the image. The digital intermediate permits "cinematographers and directors to alter colors and other image elements by working directly on the hues of pixels in what was now an additive color system in place to the subtractive system that film employed," 21 and ensured that digital visual effects could coexist with other facets of filmmaking. ${ }^{22}$

The notion that new forms of technology often replicate previous obsolete technologies is important to this thesis; Jay David Bolter and Richard Grusin refer to this concept as "remediation." As exploring this concept is also essential for this thesis, a short introduction to this remediation is necessary. Bolter and Grusin define remediation as "the way in which one medium is seen by our culture as reforming or improving upon another," 23 a process that has been happening for centuries, affecting media as diverse as paintings, novels, and television. ${ }^{24}$ Lev Manovich, another theorist concerned with digital cinema and the index, recognizes the various ways in which digital cinema remediates elements of early cinema and animation:

Seen in this context, the manual construction of images in digital cinema represents a return to the pro-cinematic practices of the nineteenth century, when images were hand-painted and hand-animated. At the turn of the twentieth century, cinema was to delegate these manual techniques to animation and define itself as a recording medium. As cinema enters the digital age, these techniques are again becoming commonplace in the filmmaking process. Consequently, cinema can no longer be

\footnotetext{
${ }^{20}$ ibid 58

${ }^{21}$ Prince 70

${ }^{22}$ ibid 71

${ }^{23}$ Jay David Bolter and Richard Grusin, Remediation: Understanding New Media (Cambridge, Mass.: MIT Press, 1999), 59.

${ }^{24}$ ibid 11
} 
clearly distinguished from animation. It is no longer an indexical media technology, but, rather, a subgenre of painting. ${ }^{25}$

Manovich's arguments about digital cinema sharing more similarities with animation and repurposing techniques from early in cinema's history are great examples of remediation. A new medium, digital cinema, is markedly distinct from previous media, though it continues to borrow techniques from previous media until it can establish itself as a unique medium. Remediation, as well as Manovich's writings on digital cinema, will be more thoroughly in the following chapters of this thesis, particularly in reference to how remediation is deployed in each of the analyzed films.

Finally, the term "nostalgia" is key to this thesis because nostalgia can be used to describe a homesick longing for the past while also looking to the past for inspiration. Marc Le Sueur outlines two main varieties of nostalgia, both of which will be discussed in this thesis: restorative and melancholic. ${ }^{26}$ Melancholic nostalgia, the more well-known version of nostalgia, is escapist and wistful in nature; those engaging in melancholic nostalgia often wish to return to a romanticized version of the past. ${ }^{27}$ Restorative nostalgia is slightly different, instead using a certain historical era as a beacon of inspiration to revitalize current art and modes of thought. ${ }^{28}$ Le Sueur believes that restorative nostalgia first appeared during the Renaissance, as intellectuals looked to Classical Antiquity to restructure Italy during the 15 th and 16 th centuries. ${ }^{29}$ The films discussed in this thesis engage in both melancholic and restorative nostalgia, celebrating the time

\footnotetext{
${ }^{25}$ Lev Manovich, The Language of New Media (Cambridge, Mass.: MIT Press, 2001), 295.

${ }^{26}$ Marc Le Sueur, “Theory Number Five: Anatomy of Nostalgia Films: Heritage and Methods," Journal of Popular Film 6.2 (1977): 188-189.

${ }^{27}$ ibid 189

${ }^{28}$ ibid 188

${ }^{29}$ ibid 188
} 
periods before digital cinema appeared. The tendency to reproduce celluloid film styles is indicative of contemporary filmmakers using celluloid as a historical beacon to discipline the new medium of digital cinema.

This thesis will be divided into three chapters, each focusing on a specific film and era of digital filmmaking in popular cinema. Chapter One will focus on Pleasantville (Gary Ross, 1998), the first Hollywood feature film to use a digital intermediate for visual effects ${ }^{30}$; it also critically examines how nostalgia can influence popular culture and one's personal life.

Pleasantville focuses on twins David (Tobey Maguire) and Jen (Reese Witherspoon), who are trapped in the world of the fictional 1950s sitcom Pleasantville after a visit from a mysterious television repairman (Don Knotts). The chapter will begin with examining how the digital intermediary was used to recreate the monochrome aesthetics of a 1950s sitcom and the bright, three-strip Technicolor aesthetic commonly seen in 1950s films. The question of the popularity of nostalgia, specifically in the 1950s, will also be discussed, using Christine Sprengler's book Screening Nostalgia: Populuxe Props and Technicolor Aesthetics in Contemporary American Film. The role of nostalgia in the film will also be analyzed, including why characters partake in nostalgia, how they respond to nostalgia, and the position of director Gary Ross on the issue. Finally, the link between nostalgia and the digital intermediary will be thoroughly dissected, allowing for an exploration of what Ross was trying to accomplish with this film, as well as how spectators may respond to the nostalgia presented in the film. This chapter will allow for a thorough examination of how digital techniques were used for the purpose of nostalgia in popular cinema even as the practice was newly implemented.

\footnotetext{
${ }^{30}$ Bob Fisher, "Black-and-White in Color," American Cinematographer 79, no. 11 (1998): 60.
} 
The second chapter will centre on The Aviator (Martin Scorsese, 2004), a biopic about eccentric billionaire Howard Hughes. Scorsese and his production crew used several different practical and digital filmmaking techniques to recreate the aesthetics of two- and three-strip Technicolor; the colours displayed onscreen change as Hughes ages, following production trends popular during Hughes' lifetime. In this chapter, Scorsese's use of both digital and practical special effects will be examined; his choice to use both when creating Hughes' mid-twentieth century world exemplifies the tension between cinema's past and present. The use of practical special effects in digital cinema will also be considered, as Scorsese's use of special effects that originated in early Hollywood films demonstrates that a use for non-digital effects remains even as Hollywood enters the digital era. An overview of how digital filmmaking techniques evolved between the production of Pleasantville and this film will be included as well. The role of nostalgia in The Aviator will also be analyzed, particularly in relation to remembering and celebrating the life of a real person. Additionally, using sources such as Pam Cook's book Screening the Past: Memory and Nostalgia in Cinema, the use of nostalgia in Scorsese's other films will be considered, adding an auteurist element to this chapter.

The third and final chapter of this thesis will analyze the recent film The Artist (Michel Hazanavicius, 2011), a film which explores nostalgia in a very different way compared to the previously mentioned films. The Artist was produced outside of the Hollywood studio system, and it completely recreates the style of a silent film from the 1920s, both aesthetically and narratively. The Artist focuses on Hollywood star George Valentin (Jean Dujardin), whose career begins to fail as synchronized sound films are introduced. His narrative is contrasted with that of Peppy Miller (Bérénice Bejo), a starlet who rose to fame after the introduction of synchronized 
sound. The film provides a romanticized, yet critical account of the Hollywood star system in the late 1920s and early 1930s. The fascination with an earlier, similarly dramatic technological change in the cinema during cinema's digital transition is interesting, and The Artist uses this to create an exploration of nostalgia for the 1920s. The film's attempt to remediate a specific subset of a particular medium - silent film - will also be explored. While the production crew of The Artist did not directly experience the transition to synchronized sound, the aesthetic and economic disruption associated with the transition is very well-known. It is possible that the transition to digital cinema may be just as disruptive as the advent of sound, and the hope that this transition will end as successfully as the transition to synchronized sound may explain the film's nostalgic perspective toward this time period.

As outlined in this introduction, exploring the use of photorealistic digital visual effects will prove to be an incredibly rich and fascinating subject. By incorporating writings on digital film theory, nostalgia, and indexicality, this thesis will attempt to explore many of the reasons behind using the digital intermediate and other techniques to recreate cinema of the past. Avoiding the debates surrounding whether the digitization of cinema is positive or negative will allow for a thorough examination of a specific nostalgic style that has emerged as a response to this transition. Perhaps this will lead to a different understanding of digital cinema and how filmmakers approach both film history and issues that are developing within digital cinema. 


\section{Chapter One: Pleasantville}

The 1950s has long been the most ubiquitous object of nostalgia, with its popularity starting in the early 1970s, as the Baby Boomer generation looked back wistfully to that earlier era as an age of innocence and affluence. ${ }^{31}$ The Boomers' began a trend across North America, with nostalgia for the 1950s appearing in magazines, films such as American Graffiti (George Lucas, 1973), and television shows such as Happy Days (1974-1984). ${ }^{32}$ The “...stability, prosperity, and military prowess" of the 1950 s was contrasted with the instability and social changes of the 1970s and 1980s, ${ }^{33}$ and the 1950s has remained a popular object of nostalgia, with more recent films such as Far From Heaven (Todd Haynes, 2002), a Douglas Sirk-inspired melodrama, continuing the trend.

Pleasantville (Gary Ross, 1998) is a particularly interesting example of recent 1950s nostalgia in film, and is significantly richer than other nostalgia films both technically and thematically. Pleasantville focuses on teenage siblings, nerdy David (Tobey Maguire) and popular Jen (Reese Witherspoon), who become trapped in the fictional 1950s sitcom Pleasantville after a mysterious television repairman (Don Knotts) discovers David's love for the show. The teenagers must adjust to their new life in the 1950s black-and-white sitcom world, playing Bud and Mary-Sue Parker. They develop relationships with their sitcom parents George (William H. Macy) and Betty (Joan Allen), and other residents of Pleasantville, like soda shop owner Bill Johnson (Jeff Daniels). However, as the teens introduce 1990s behaviours and values,

\footnotetext{
${ }^{31}$ Christine Sprengler, Screening Nostalgia: Populuxe Props and Technicolor Aesthetics in Contemporary American Film (New York: Berghan Books, 2009), 43.

32 ibid 43-45

${ }^{33}$ ibid $48-49$
} 
small instances of colour begin appearing throughout the town, representing the modernisation of the characters and their lives, but drawing the ire of old-fashioned mayor Big Bob (J.T. Walsh) and other residents, who are resistant to such change. Despite such resistance, the monochrome world of Pleasantville is eventually transformed into a world of full color.

To achieve this effect, Gary Ross employed extensive digital postproduction techniques, and was the first director in mainstream Hollywood cinema to use a digital intermediate. ${ }^{34}$ Ross used the digital intermediate to both create the monochrome effect of a 1950s sitcom town, and to gradually incorporate the bright Technicolor-inspired hues. This process was very different than that used in Far From Heaven, which had Todd Haynes recreating the oversaturated Technicolor style of Douglas Sirk’s films by using actual filmmaking techniques from the 1950s. ${ }^{35}$ Thematically, Pleasantville explores the concepts of memory, nostalgia, and social change, featuring many emotional scenes that demonstrate how various characters navigate cultural and social progress. I will examine how the use of the digital intermediate to recreate various 1950s televisual aesthetics comes the basis to explore themes related to nostalgia, memory and social and technological change. First, the use of the digital intermediate in Pleasantville will be discussed in more detail. An analysis of the treatment of nostalgia in the film will follow, and examine how this treatment affects both characters and audience members. Finally, the chapter will conclude with a discussion of how the use of the digital intermediate and themes of nostalgia in Pleasantville may be indicative of an uncertainty toward change, both on a personal level and in terms of film production practices.

\footnotetext{
${ }^{34}$ Bob Fisher, "Black-and-White in Color," American Cinematographer 79, no. 11 (1998): 60.

35 Jon Silber, “A Scandal in Suburbia,” American Cinematographer 83, no. 12 (2002): 56-58.
} 


\section{"Must Be Awfully Lucky to See Colours Like That": Pleasantville and Digital Colour}

The sudden and surprising bursts of bright Technicolor-inspired hues, which slowly fill in the monochrome world of Pleasantville, are one of the most memorable and distinctive elements of the film, but it was not obvious how such an effect could be acheived with existing film technology. Stephen Prince notes that the film's “symbolic use of color to shift to a fantasy world closer to reality could not have been accomplished via traditional film timing." ${ }^{36}$ The digital intermediate was the only process that would allow the director Ross to highlight individual elements within the frame to be colorized. The digital intermediate process was thus essential to the director's vision of the film, and it creates a connection with the themes of memory and nostalgia that Pleasantville explores. Perhaps ironically, only the latest digital technology of the modern era could reproduce the earlier and supposedly simpler time that is being nostalgically recalled. As the connection between the use of digital tools and nostalgia in Pleasantville is being examined in this chapter, an overview of Pleasantville's use of the digital intermediate is necessary.

As previously outlined, the term "digital intermediate" refers to the process of converting celluloid into a data file, modifying the images, and transferring the images back to celluloid. ${ }^{37}$ Its importance stems from the level of digitization and how that affects the image:

Digital technology has been used for years for film editing, computer-generated imagery, and special effects. What's new about the DI process is that it involves the digitization of all or nearly all of the film's images, rather than the partial

\footnotetext{
${ }^{36}$ Stephen Prince, Digital Visual Effects in Cinema: The Seduction of Reality (New Brunswick, New Jersey: Rutgers University Press, 2012), 73.

${ }^{37}$ John Belton, “Painting by Numbers: The Digital Intermediate," Film Quarterly 61.3 (2008): 58.
} 
digitization involved in these earlier features of the post-production workflow. As such, it marks an important extension of the digitization of the cinema. ${ }^{38}$

Digitizing almost all of the images found in a film allows the filmmaker a great deal of control over the image. Stephen Prince points out that filmmakers can use the digital intermediate to more precisely correct colour or other errors in the image than with traditional print methods. ${ }^{39}$

John Belton notes that while the digital intermediate can be used for almost any post-production process, it is primarily used for colour grading or manipulation, ${ }^{40}$ enabling filmmakers to experiment with a variety of aesthetics and styles.

Pleasantville was the first live-action feature-length film to use a digital intermediate to create visual effects; approximately 163,000 frames of $35 \mathrm{~mm}$ film were digitally manipulated. ${ }^{41}$ Director Gary Ross worked with staff, including producer Bob Degus, visual effects supervisor Chris Watts, colour effects designer Michael Southard, and director of photography John Lindley to recreate a visual aesthetic similar to that of a 1950 s television sitcom. ${ }^{42}$ Lindley and Ross also debated shooting Pleasantville on black-and-white film stock, but ultimately used colour stock after tests revealed that images shot on black-on-white film would lose their sharpness after digitization. ${ }^{43}$ Lindley adjusted lighting in various scenes to accommodate the conversion of colour film to black-and-white, using hard light on monochrome and softer light on colour characters when they appeared in the same scene. ${ }^{44}$ The crew also researched practical

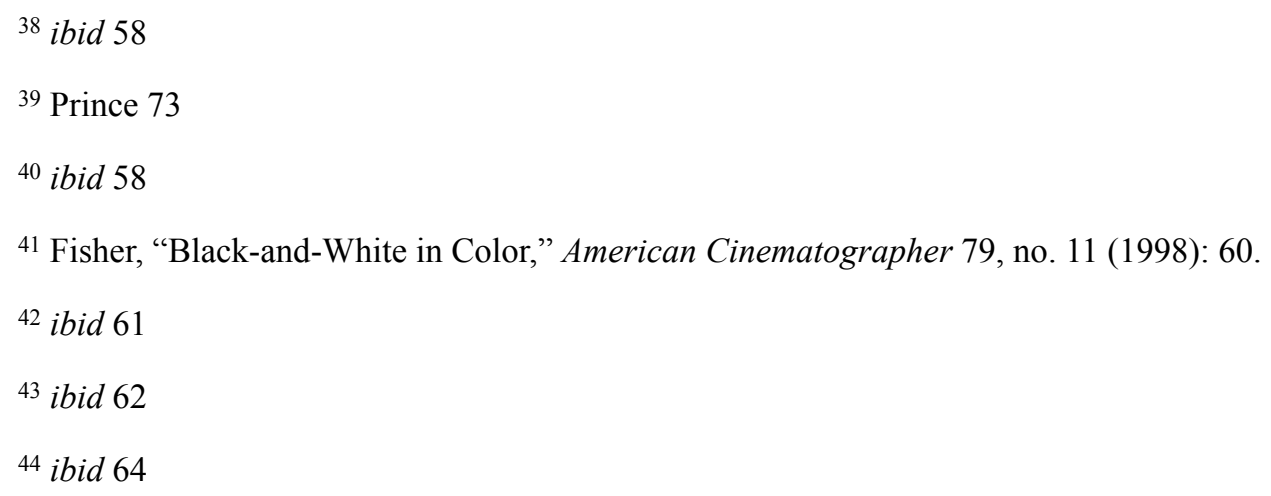


filmmaking techniques used in the 1950s, and incorporated them where possible. Pleasantville was shot using 1.85:1 spherical format, ${ }^{45}$ while Lindley also used $40 \mathrm{~mm}$ lenses,${ }^{46}$ both of which were commonly used in 1950s television and filmmaking. As the characters in the film began to appear in colour and their beliefs became more modern, Lindley highlighted this with more aggressive camera movement and longer lenses. ${ }^{47}$

Though the technical aspects of Pleasantville are quite impressive, Ross does not allow the digital effects to be the primary focus of the film; instead, he incorporated the digitally altered colour into the narrative:

What makes [Pleasantville] unique is that it narrativizes the presence and absence of color and black-and-white. In this way, the film becomes a text about color, black-and-white, and the relationship between the two.....the fact that it does so from a vantage point of digital technology's ability to manipulate images is important for our understanding of cinema in the digital age. ${ }^{48}$

As Belton suggests here, Ross' use of colour is not solely to create spectacle. Paul Grainge also recognizes this, and explains that "digital capacities of visual manipulation are used to create a myth-world where chromatic difference becomes the narrative lynchpin," ${ }^{\prime 9}$ as opposed to the novelty or shock of Ross' colour entertaining the audience in a manner akin to the Cinema of Attractions. ${ }^{50}$ Many of the scenes primarily focusing on colour in Pleasantville are either essential to the film's narrative or intended to create an emotional response in the audience.

\footnotetext{
${ }^{45}$ ibid 62

${ }^{46}$ ibid 65

${ }^{47}$ ibid 65

${ }^{48}$ Belton, "Painting by Numbers" 60

49 Paul Grainge, "Colouring the Past: Pleasantville and the Textuality of Media Memory," in Memory and Popular Film, ed. Paul Grainge (Manchester: Manchester University Press, 2003), 214.

${ }^{50}$ See Tom Gunning, "The Cinema of Attractions: Early Film, Its Spectator and the Avant-Garde," in Early Cinema: Space Frame Narrative, ed. Thomas Elsaesser (London: British Film Institute, 1990), 56-62.
} 
Two of the most technically impressive sequences in Pleasantville involve poignant moments with Betty Parker and her makeup. After Jen/Mary-Sue teaches her about masturbation, Betty becomes one of the colourful residents of Pleasantville. Needing to hide this from George and mayor of Pleasantville Big Bob, who are firmly positioned against colour, David/Bud helps Betty apply her still monochrome makeup to hide her new complexion from her husband. The sequence is composed of extreme close-ups of Betty's face, lips, and arms being returned to their original monochromatic hue by her grey makeup which is delicately applied by David/Bud. Soon Betty's return to black and white is complete, save for her piercing green eyes. She emotionally asks David/Bud if George will notice her disguise, causing David/Bud to reassure her. In a later scene, Betty enters the soda shop after seeing Bill Johnson's artwork in the window. Bill shows her a book of artwork given to him by Bud, and one of the paintings moves Betty. As she wipes a tear from her cheek, Betty's grey makeup becomes noticeable on her white glove. Bill stops her from leaving, and proceeds to gently wash the makeup off her face. After the makeup is removed, Bill is in awe of Betty's colourful appearance, and is inspired to paint her.

Both moments are deliberately crafted to display both the power of the digital intermediate and to allow audience members to identify with Betty. David/Bud's long, slow swipes when applying the makeup and Bill's tender dabs when removing it allow spectators to look closely at this new technology, as they see immediately see colour appear and/or disappear, largely unseen in Hollywood films until Pleasantville's release. While this new technology is being presented, the audience is also encouraged to connect with Betty, empathizing with her as she must repress her true self for George when she applies the makeup, and feeling delight as she reconnects with Bill, who appreciates her for her true identity. 
While Pleasantville's use of the digital intermediate was groundbreaking when it was initially released, it has received some criticism for the way digital colour was employed. John Belton was disappointed that Ross did not challenge the status-quo of the image more emphatically with this new technology:

DI gives filmmakers the possibility of penetrating traditional barriers. It enables them to create a new chromatic spectrum that includes both black-and-white and color. Pleasantville opens a door onto innovation, but then it retreats to convention. In this sense, it mirrors the course of digital imaging technology which tends to simulate older, analogue, image-making conventions, not to create radically new perceptual modes. ${ }^{51}$

Despite Pleasantville being the first Hollywood feature-length film to use the digital intermediate, Ross' reluctance to create wholly new forms or styles is perhaps understandable in the relatively conservative context of Hollywood filmmaking. As D.N. Rodowick has observed, new digital technologies were mainly been used for the recreation of past media forms:

Curiously, for an industry driven by innovation and market differentiation, the qualities of the "photographic" and the "cinematic" remain resolutely the touchstones for creative achievement in digital imaging entertainment. The "new" has not been sought in digital imaging as much as fresh means for producing familiar effects with a long cultural history, though often in very novel contexts. ${ }^{52}$

This fixation on replicating the aesthetic qualities of the "photographic" and the "cinematic" has also been considered by Jay David Bolter and Richard Grusin, who describe the in fact quite complex process of technological change, which is rarely if ever straightforwardly progressive.

They write:

Digital visual media can best be understood through the ways in which they honor, rival, and revise linear-perspective painting, photography, film, television, and print. No medium today, and certainly no single media event, seems to do its

\footnotetext{
${ }^{51}$ Belton "Painting by Numbers" 61

${ }^{52}$ D.N. Rodowick, The Virtual Life of Film (Cambridge, Mass.: Harvard University Press, 2007), 101.
} 
cultural work in isolation from other media, any more than it works in isolation from other social and economic forces. What is new about new media comes from the particular ways in which they refashion older media and the ways in which older media refashion themselves to answer the challenges of new media. ${ }^{53}$

Examining Pleasantville using Bolter and Grusin's argument about new media, one can see that Ross deliberately crafted the film to be in conversation with various older media. Though Pleasantville is a film that was created using digital tools, it refashions the aesthetics of 1950s television visually, aurally, and narratively. Ross expects the audience to understand this connection and detect cues that reference these media forms; referencing these older technologies and tropes also connects with the film's examination of nostalgia. For example, Ross references several tropes associated with 1950s television and the strict censorship of the era: Jen discovers that there are no toilets in any of the town's washrooms; that nobody in Pleasantville knows anything about sex; and double beds are introduced and later restricted under Big Bob's rules. The humour inherent in these moments is lost on a spectator who is unaware of the relevant conventions. The film's shift from monochrome to colour emphasizes both the comedic tone and the 1950s references, allowing the spectator to connect with the new technology while being made aware of the ways in which 1950s television has been refashioned.

This reusing of past cinematic aesthetics also complicates the common claim that the cinema needs to maintain the illusion of strictly capturing reality, as expressed for example by Lev Manovich:

[C]inema works hard to erase any traces of its own production process, including any indication that the images that we see could have been constructed rather

\footnotetext{
53 Jay David Bolter and Richard Grusin, Remediation: Understanding New Media (Cambridge, Mass.: MIT Press, 1999), 15.
} 
than simply recorded. It denies the reality it shows often does not exist outside the film image, an image arrived at by photographing an already impossible space, itself put together with the use of models, mirrors, and matte paintings, and then combined with other images through optical printing. It pretends to be a simple recording of an already existing reality - both to the viewer and itself. ${ }^{54}$

Manovich's discussion is interesting when connected to the digital recreation of celluloidexclusive film styles. These recreations seem actually to highlight the false indexicality of film; they accentuate the fact that these images are unable to exist outside of the film's reality. This is especially apparent in Pleasantville, as the film's narrative brings "real" characters David and Jen into a false reality thought not to exist outside of the film, or in this case television, image. Watching David and Jen inhabit new roles and interact with this previous artificial world, the spectator can then become aware of the falseness of the image seen onscreen. This falseness is continually emphasized as the world of Pleasantville is launched into colour. Pleasantville appears more "realistic" when in colour and as it slowly sheds its sitcom conventions, though the artifice remains evident as the colour that appears in Pleasantville is the bright, oversaturated colour created by three-strip Technicolor. "True" reality, seen when David/Bud returns from Pleasantville, does not seem to have had any colour manipulation via the digital intermediate, concealing its cinematic origins from the spectator. Thus, Pleasantville uses the digital intermediate to demystify and to flaunt the wonders of digital filmmaking tools, while also emphasizing the falsity of the cinematic image. These ideas are all examined through Pleasantville's narrative, allowing the film to use this technology for more than pure spectacle.

\footnotetext{
${ }^{54}$ Lev Manovich, The Language of New Media, 298-299.
} 


\section{"A Kinder, Gentler Time...": The Role of Nostalgia in Pleasantville}

Belton's previously quoted analysis of Pleasantville and colourization refers to nostalgia, specifically how colourization allows ourselves to be freed from nostalgia for a black-and-white past. ${ }^{55}$ Though Belton's interpretation of the film is not incorrect, Pleasantville's exploration of nostalgia is slightly more sophisticated than he implies. By using various constructs of 1950s nostalgia and developing assorted characters with unique methods of coping with change, Pleasantville creates an intriguing depiction of how one reconciles the past with an everchanging present and future.

Since Pleasantville examines themes related to nostalgia and memory, it inevitably fixates on specific objects of nostalgia, most notably the mythical representation of a "utopian" 1950s. As noted by Christine Sprengler, the 1950s is one of the most well-known objects of nostalgia, and is the decade which most nostalgia-based industries and popular culture focus on. ${ }^{56}$ The "mythical", nostalgic construct of the 1950s has become the most dominant representation of the decade, with associations being made with family values, prosperity, and suburbia. These representations are a fabrication courtesy of both collective and individual imaginations, though they do have strong connections to social, political, and material realities. ${ }^{57}$ Nostalgic representations of the 1950s tend to mythologize various specific phenomena, such as rock-and-roll and poodle skirts, while also creating myths about the stability and prosperity

\footnotetext{
${ }^{55}$ Belton "Painting by Numbers" 63

${ }^{56}$ Sprengler 39

${ }^{57}$ ibid 40
} 
experienced after World War II. ${ }^{58}$ On film, nostalgia for the 1950s first appeared in The Last Picture Show (Peter Bogdanovich, 1971) and television series like Happy Days (1974-1984). ${ }^{59}$ These television series and films from the 1970s had to rely more on formal conventions to communicate their "Fifties-ness" to the audience, as the 1950s remained fresh in viewers' minds; 1970s television sitcoms often had to share airtime with reruns of 1950 s sitcoms. ${ }^{60}$ Nostalgia for the "simpler" 1950s was also a reaction to the social and political turmoil of the 1960s and 1970s, with the Women's Movement, the Civil Rights Movements, and the 1970s economic recession causing upheaval for many Americans. ${ }^{61}$

While Sprengler describes several strains of 1950s nostalgia exist, including what she calls the "Lounge Fifties", the "Hollywood Fifties", she argues that the most prevalent strain is the "Populuxe Fifties," ${ }^{\prime 2}$ which focused on postwar prosperity, materialism, and exaggerated styles. ${ }^{63}$ "Populuxe" is Sprengler's term to describe a specific contemporary attitude towards 1950s consumption culture, the new visual flamboyance in design, and the various economic values that defined post-World War II life ${ }^{64}$ Specific objects and artifacts are used to create the Populuxe look, such as pink toasters and tail-finned cars, which can embody the various social

\footnotetext{
${ }^{58}$ ibid $40-41$

${ }^{59}$ ibid 43-45

60 ibid 49

${ }^{61}$ ibid $46-47$

${ }^{62}$ ibid $41-42$

${ }^{63}$ ibid 42

${ }^{64}$ ibid 43
} 
and political values of the $1950 \mathrm{~s} .{ }^{65}$ Populuxe is also prominent in the 'retro film,' one of the many forms that nostalgia can take:

The 'retro film' mobilises particular codes that have come to connote a past sensibility as it is selectively re-remembered in the present (i.e. 'the seventies' or 'the sixties') as a structure of feeling, and these codes function metonymically, standing in for the entire decade. As such, the retro film is less concerned with historical accuracy than with a playful deployment of codes that connote pastness. $^{66}$

Sprengler also notes that "it is precisely this ability to encapsulate and communicate relatively specific meanings that renders the visual culture of the Fifties so potent in the 1970 s as well as contemporary expressions of nostalgia," 67 explaining why Populuxe is often used to denote the 1950s in nostalgia or 'retro' films.

Pleasantville deploys many of the tropes of 1950s nostalgia noted by Sprengler, as well as various aspects of the retro film, but to craft its quite conscious examination and reappraisal of nostalgia. Nostalgia is not depicted as inherently harmful, unless characters engage with it to the point of refusing to accept any change in their lives. Pleasantville's intent to explore the concept of nostalgia is made evident with the first sequence of the film. The film opens with a commercial promoting the fictional TV Time network, which broadcasts syndicated reruns of sitcoms from the 1950s, allowing viewers to partake in nostalgia at their convenience. The commercial references several 1950s sitcoms, including The Honeymooners, I Love Lucy, and Make Room for Daddy, displaying images from these programs on 1950s-era televisions. The graphics and font featured in the commercial evoke a sense of the nostalgic construct of the

\footnotetext{
${ }^{65}$ ibid 49

${ }^{66}$ Philip Drake, “"Mortgaged to Music: New Retro Movies in 1990s Hollywood Cinema,” in Memory and Popular Film, ed. Paul Grainge (Manchester: Manchester University Press, 2003), 188.

${ }^{67}$ Sprengler 49
} 
Fifties. The announcer goes on to promote an upcoming marathon of the sitcom Pleasantville, the show-within-a-movie that eventually becomes the film's main setting. The Pleasantville marathon is described as "twenty-four hours chock full of family values," a "scrapbook full of all your favourite Pleasantville memories," and viewers are encouraged to "flashback to kinder, gentler times," all three of these descriptors referencing the 1950s utopian ideal of prosperity and families in suburbia. The nostalgic construct of the Fifties as being safe and family-friendly is immediately contrasted with David and Jen's late-1990s high school. Students, particularly Jen, are depicted as being promiscuous, impolite, and shallow. Teachers lecture about the harsh reality of the modern world, including poor job prospects, the prevalence of sexually transmitted diseases like HIV, and the threat of global warming. David finds comfort in the sitcom Pleasantville, and uses it to escape from his difficult family and social life; his parents have divorced, something that was very uncommon during the 1950s. The negative aspects of life in the 1990s are deliberately exaggerated to stress the simplicity of life during the mythical 1950s, while disregarding the darker aspects of the 1950s, like institutional racism, poverty, and McCarthyism. ${ }^{68}$

Pleasantville's use of nostalgia and memory can best be analyzed by examining protagonists David and Jen. David and Jen often clash, with Jen considering David's love of Pleasantville to be "dorky," and David not understanding his sister's fixation with popularity. David's fascination with a 1950s sitcom is not insignificant; television became one of the most important aspects of 1950s life. Television encouraged conspicuous consumption, appropriate behaviour for consumers, and promoted the idea of the American dream. ${ }^{69}$ Additionally, family

\footnotetext{
${ }^{68}$ ibid 41

${ }^{69}$ ibid 49
} 
sitcoms provided an ideal for viewers to pursue, while also providing guidance, as outlined by Sprengler:

[1950s domestic sitcoms] showcased on a weekly basis the morality and prosperity of the 'average' American family, one that was, almost without exception white, Protestant, middle-class, nuclear and suburban. These programs supplied the viewer with specific models of familial behaviour and organization, solutions to problems encountered in the domestic sphere, and resolutions to morally ambiguous situations. Avoiding serious subject matter and treating trivial dilemmas as all-important, these programmes represented for their 1950s audiences, if not reality, at least a glorified normality to which they ought to aspire. ${ }^{70}$

The town of Pleasantville is an excellent example of a 1950s domestic sitcom taking "glorified normality" to an absurd extreme. First, negative emotions do not seem to exist in Pleasantville; Mayor Big Bob becomes colourful after David antagonizes him into exhibiting anger instead of his usual pleasant demeanour. Schooling is also very basic, possibly to avoid uncomfortable subject matter, and Jen discovers that the books in the local library are blank. Pleasantville's weather forecast is always "...another sunny day - high 72 , low 72 , and not a cloud in the sky," and none of the residents have seen rain. Additionally, Pleasantville does not experience disasters such as flooding or fires; the local fire department solely exists to rescue cats from trees. While David is initially charmed by Pleasantville, both he and Jen grow to find the town's banal perfection to be unsettling, causing David to eventually accept changes to the town.

David's interest in the Pleasantville sitcom can also be linked with Sprengler's analysis of the domestic sitcom's importance. It is implied that David's love of Pleasantville is a coping mechanism; he is having difficulties with his home and social lives. His parents' divorce and unpopularity weigh on him heavily, and experiencing the idealized family and town from a past

${ }^{70}$ ibid 50 
era is soothing for him. Consequently, David is pleased after the mysterious television repairman sends him and his sister into the world of Pleasantville, as he can finally experience the family and social life he desires by taking on the role of Bud Parker. David uses this new role as an opportunity to reinvent himself, first welcoming his new position in the nostalgic world of Pleasantville. David easily adapts to 1950 s life, enjoying a hearty breakfast with stereotypical 1950s parents George and Betty, chatting with the Parkers' neighbours, excelling at basketball practice, and disapproving of Jen's sexual antics. After realizing he can educate the citizens of Pleasantville about academics, particularly art and literature, David begins to accept and encourage change in Pleasantville. This change allows David to become more confident, resulting in him gaining a love interest in Margaret Henderson (Marley Shelton). He also earns his colours after standing up to some monochrome bullies who are harassing Betty, ${ }^{71}$ demonstrating an assertiveness he lacked in his 1990s life. David's opinions on nostalgia eventually come full circle, as he delivers a poignant speech emphasizing the need for change in life and the importance of not living through one's memories. He practices this himself as he chooses to leave the Pleasantville universe and return to his modern 1990s life, using his newfound knowledge about change to aid his 1990s mother (Jane Kaczmarek).

While David initially uses nostalgia as an escape from his unhappy life, Jen enjoys her modern life and has difficulty adjusting to life in the mythical 1950s. Compared to her life in the 1990s, Jen behaves much the same in Pleasantville, remaining stubborn, shallow, and amorous. Jen's reluctance to inhabit the role of Mary-Sue Parker results in her permanently altering the

\footnotetext{
${ }^{71}$ The prejudice and divide between Pleasantville's monochrome and colourful people directly mirrors the racism seen in the United States during the 1950s. Ross uses the town's transformation into colour to comment on the nostalgic tendency of downplaying negative aspects of past eras, including societal issues like racism. While this aspect of Pleasantville certainly warrants further discussion, I felt that I would be unable to do justice to this material due to length restraints.
} 
town with the introduction of modern slang and sexual behaviour, after a tryst with basketball start Skip Martin (Paul Walker). Soon, she wonders why she remains in black and white despite engaging in the same behaviours that render her classmates colourful; David advises her that becoming colourful may be caused by more than sex. As literature is introduced to Pleasantville and reading becomes trendy among the town's teenagers, Jen finds herself swept up in the trend. She slowly becomes more focused on academics, even declining a date with Skip in favour of staying in to read a novel. At the film's conclusion, Jen decides to stay in Pleasantville universe to attend college, acknowledging that she may not have the opportunity due to her substandard grades in the 1990s. Jen's time in Pleasantville demonstrates that fully embracing modernity is not necessarily the key to a successful life; nostalgia or considering the past may have some value.

The overexaggeration of the mythical 1950s and the development of the protagonists in Pleasantville combine to create a neutral message about nostalgia and progress. While change is important and necessary in life, engaging in nostalgia is acceptable, to a certain degree. Jen shows that completely embracing modernity is not the only valid way to live, as she develops an increased interest in academics during her time in Pleasantville. However, David's obsessive engagement with the Pleasantville sitcom is also unacceptable, as he closes himself off from new experiences. Elements of the past and the present have value; dismissing or elevating either of them is not conducive to living a satisfying life. The refusal to completely revere the past and the deconstruction of the mythical 1950s show that Pleasantville is not a pure nostalgia film. 


\section{"You Don’t Deserve to Live in This Paradise!": A Nostalgia for Celluloid?}

Pleasantville celebrates the arrival of the digital intermediate, demonstrating the capabilities of this new technology by displaying selected portions of the image in colour. The film also examines various attitudes concerning nostalgia, memory, and progress. Though the two threads initially appear to be unrelated, the digital intermediate and themes relating to nostalgia in the narrative combine to form an argument about progress and the refusal to change that reflects the critical divide between analog and digital cinema. As director Gary Ross uses various characters to call attention to the abilities of the digital intermediate and to analyze aspects of nostalgia, it is only appropriate that another character, Don Knotts' television repairman, allows for the perfect opportunity analyze both the social and technological aspects of this film.

Paul Grainge notes a significant connection between Pleasantville and media criticism, arguing that the film can be read as a reinterpretation of the debates surrounding digital colourization of black and white films. ${ }^{72}$ Grainge notes that colourization critics argued that the process "...created movies that were hollow simulations" 73 of black and white films, though stances toward digital colourization eventually changed as the process was used to produce Hollywood films with sophisticated visual effects. ${ }^{74}$ Pleasantville can thus be interpreted as a response to the colourization debate and the eventual embrace of digital colourization in different contexts:

\footnotetext{
${ }^{72}$ Grainge 213

${ }^{73}$ ibid 213

${ }^{74}$ ibid 213
} 
...Pleasantville reflects a changing attitude towards the digital re-presentation of the past. To detractors of the colourisation process, colour conversion tampered with the aura (the artefact) and the era (the tradition) of the 'classic' black and white movie. At stake in the colourisation debate, and especially felt by the Hollywood establishment, was the destabilisation of categories of value such as 'authenticity' and 'the archive'; digital technology was seen to challenge the visual and cultural basis upon which these categories have been traditionally grounded and sustained. However, as computer technology has been absorbed within cultural life.....digital imaging/information has become less of a threat and more an intrinsic part of (new) media life. ${ }^{75}$

Grainge's analysis can be supported by examining some of the attitudes of Pleasantville characters: Jen is initially in favour of colourizing the town, though she comes to appreciate less modern aspects of 1950s life; David is against colourization, eventually embracing it after more time in the town; George and Big Bob are staunchly against it. The mysterious repairman is also anti-colour, as he is heavily invested in maintaining the tradition surrounding the black-andwhite Pleasantville. However, this interpretation of Pleasantville does have flaws, with John Belton noting that Grainge "rewrites the 'trauma' of colorization as a form of rejuvenation rather than as an Orwellian rewriting of the past." ${ }^{76}$ Interestingly, Grainge's colourization argument can be modified and applied to the digitization debate surrounding cinema. The characters' positions concerning colourization can also be interpreted as their stance regarding digitization; the debates surrounding colour also mirror various arguments regarding digital cinema. Possibly the most interesting supporting character in Pleasantville, the mysterious television repairman combines the technological with issues surrounding nostalgia, meaning his character can possibly be analyzed as an argument against the detractors of digital cinematic technologies.

\footnotetext{
${ }^{75}$ ibid 215

${ }^{76}$ Belton "Painting by the Numbers" 63
} 
The repairman wants to remember the 1950 s as the mythical, nostalgic construct presented in the Pleasantville television series. He prefers to keep Pleasantville from changing, assuming the town's residents were happier before the twins' arrival, and he truly believes that cementing the town within the mythical 1950s is in everyone's best interest. The casting of Don Knotts also creates an offscreen connection between the repairman and nostalgia, as Knotts appeared in The Andy Griffith Show, a 1950s sitcom associated with the mythical Fifties and used as a model for Pleasantville. The repairman's negative perception of change can be compared to similar attitudes held by writers who are critical of digital cinema and the use of the digital intermediate. One such writer, John Belton, offers an interesting interpretation of both the colour and digitization used in Pleasantville:

The use of color in Pleasantville opens a window onto our traditional understanding of the photographic image as homogenous, as a whole constituted by the frame that groups its contents together. The film's narrative explores the disruptive potential of the violation of the image's chromatic homogeneity while simultaneously setting in place a mechanism to restore that homogeneity. In this scenario, analogue continuity (figured as black-and-white) is threatened by digital discontinuity - the break-up of the image into discrete picture elements (seen in the appearance of color within a black-and-white frame). This threat is resolved by the restoration of chromatic continuity-black-and-white disappears entirely, leaving an all-color, all-the-time world. This scenario, in turn, can also be seen as a metaphor for the digitization of the cinema. In the digitization process, analogue (in the form of the pro-filmic event or film of that event) is converted to digital only to be restored to analogue (projection prints) and it is restored to an analogue that is somehow "better" for having undergone digitization. ${ }^{77}$

Belton feels that digitizing a film like Pleasantville is unnecessary, and his argument is comparable to some of the behaviours of the repairman. Like Belton's digitization metaphor, the repairman believes that the changes introduced to Pleasantville are unneeded, and that the town

\footnotetext{
${ }^{77}$ Belton, "Painting by Numbers" 59
} 
is not "better" after becoming colourful. Technologically, the repairman also appears to reject or be unfamiliar with more modern technology, such as David and Jen's 1990s television set, which may be another aspect of his dependency on nostalgia. This rejection can be inferred because, despite claiming to be a television repairman, he does not repair David's remote control, instead giving him the stylized Atomic-Age remote that transports David into Pleasantville's fictional world.

The repairman thus also exhibits attitudes akin to those of writers who are knowledgeable about cinematic technology, yet remain skeptical about the transition to digital cinema. He has a thorough knowledge and connection to technology, particularly televisions, as he is presented as a repair expert and he relies on televisions to appear in the world of Pleasantville. He demonstrates the ability to simultaneously appear on multiple screens and appears to control his appearances, as David is unable to summon him by changing channels. In a piece comparable to his criticism of digitization in Pleasantville, John Belton expresses his concerns about digital cinema as a whole, primarily focusing on the issues surrounding digital projection. He notes the continued resemblance between digital and analog cinema, remarking "All that proponents of digital projection are claiming is that it is comparable to $35 \mathrm{~mm}$. That does not sound like a revolutionary technology. ${ }^{, 78} \mathrm{He}$ also questions the speed of the transition to digital cinema, stating that "Although [digital cinema] proponents claim that within five or ten or twenty years it will have replaced film, this seems unlikely," ${ }^{, 79}$ because of factors such as the high cost of digital technology, potential issues with obsolete technology, and the need to establish industry

\footnotetext{
${ }^{78}$ John Belton, “Digital Cinema: A False Revolution,” October 100, (2002): 105.

${ }^{79}$ ibid 110
} 
standards ${ }^{80}$ Similarly, Anne Friedberg is concerned with medium specificity and digital cinema, believing that "...the apparatus we came to know as "the cinema" is being displaced by systems of circulation and transmission which abolish the projection screen and begin to link the video screens of the computer and television with the dialogic interactivity of the telephone," which will lead to further reduction of the differentiation between film, television, and the computer. ${ }^{81}$

These critics are preoccupied with a specific definition of cinema, just as the repairman fixates on specific image of Pleasantville. Change easily angers the repairman, and he is immediately coded as not originating in the modern era. Though he gently expresses his concern after some "reruns" of the television show are different, he later threatens David in the local television repair shop after the twins continue to introduce change into Pleasantville. The repairman has seemingly searched for the perfect Bud and Mary-Sue Parker to complete the town. He also uses heavy-handed symbolism to describe his perception of Pleasantville and the mythical 1950s, describing the fictional town as "paradise" and demonstrating temptation with an apple — an image of Margaret handing David a red apple at Lovers' Lane — both of which echo the story of the Garden of Eden. The repairman is convinced that Pleasantville can only exist as a product of the mythical 1950s, and that the town cannot be modified, despite David and Jen's best efforts. Similarly, many of the writers who criticize the advent of digital cinema believe that cinema can only exist in a photochemical format, claiming that any attempts to digitize cinema threaten cinema's medium specificity. The repairman stands in for these writers, who are actively

\footnotetext{
80 ibid 111

${ }^{81}$ Anne Friedberg, "The End of Cinema: Multimedia and Technological Change," in The Film Theory Reader: Debates and Arguments, ed. Marc Furstenau (London and New York: Routledge, 2010), 271.
} 
opposing the digitization of cinema. ${ }^{82}$ The town of Pleasantville acts as a metaphor for the cinema, which is being "improved" via the digital intermediate, represented by colourization. Though many residents of Pleasantville are initially confounded or disapproving of the colours that slowly overrun the town, they eventually accept the changes after a climactic speech from David, who encourages the citizens of Pleasantville to welcome change into their lives.

Pleasantville can therefore be interpreted as a defense of the use of digital tools in filmmaking, relying on both the technology and the narrative of the film to counter criticism of digital cinema. By incorporating his use of the digital intermediate into key narrative moments, he uses this technology to create effects that are more than pure spectacle. Employing the repairman as a direct argument against detractors of digital cinema, Ross demonstrates how a refusal to adapt to new ways of thinking is ultimately harmful.

\section{Conclusion}

Pleasantville first appears to be an exercise in 1950s nostalgia, deploying codes associated with the retro film to create an irreverent take on the 1950s sitcom. However, it actually provides some profound commentary on nostalgia, memory, and progress, all while exhibiting the power of the digital intermediate, a relatively new technology at the time of the film's production. Pleasantville presents the digital intermediate to audiences by incorporating its abilities into its narrative, using the colourization of the town of Pleasantville to argue in favour of digital cinematic tools. The film also examines various positions on nostalgia and progress by developing many of the film's characters, eventually concluding that a neutral approach to

\footnotetext{
${ }^{82}$ Using cinema to denounce new technologies and the belief that cinema is constantly threatened by new media forms is further discussed in Paul Young's book The Cinema Dreams Its Rivals: Media Fantasy Films From Radio to Internet (Minneapolis: University of Minnesota Press, 2006).
} 
nostalgia is best; living entirely in the past or present is not conducive to satisfaction, but completely discounting the value of history is ill-advised. Though director Gary Ross uses the digital intermediate to recreate the aesthetics of an analog medium, the 1950s domestic sitcom, he does it not just to attain the photographic ideal of the image. Instead, he uses the digital intermediate to question the relationship between the past and present, demonstrating a more nuanced use of this technology and how the proper use of digital production tools can greatly enhance a film's narrative. 


\section{Chapter Two: The Aviator}

After the release of Pleasantville, the first feature-length Hollywood film to be fully processed using the digital intermediate, use of digital cinematic tools became more common in Hollywood. In 2000, Joel and Ethan Coen released O Brother Where Art Thou?, which took a subtler approach to the digital intermediate. Instead of using the digital intermediate to create special effects, like in Pleasantville, cinematographer Roger Deakins used it to desaturate the film's colour, creating a "dusty" aesthetic resembling faded postcards. ${ }^{83}$ Some cinematographers began decrying the digital intermediate, claiming that the role of cinematographers would be diminished should directors, actors, or producers use digital colouring suites. ${ }^{84}$ Other directors and cinematographers embraced the digital intermediate, usually after determining that the technology could easily create specific effects. After researching various photochemical effects for Flags of Our Fathers in 2006, director Clint Eastwood and cinematographer Tom Stern were so pleased with the results that Eastwood used a digital intermediate in his subsequent films. ${ }^{85}$ Vilmos Zsigmond also used the digital intermediate to create a 1940s period look in The Black Dahlia (Brian DePalma, 2006). ${ }^{86}$

Interestingly, an early adopter of the digital intermediate was Martin Scorsese, who used the digital intermediate to recreate the appearance of two-strip and three-strip Technicolor in his 2004 Howard Hughes biopic The Aviator. The Aviator was the first film Scorsese used digital

\footnotetext{
${ }^{83}$ Stephen Prince, Digital Visual Effects in Cinema: The Seduction of Reality (New Brunswick, New Jersey: Rutgers University Press, 2012), 74.

${ }^{84}$ ibid 76

${ }^{85}$ ibid 75

${ }^{86}$ ibid 76
} 
tools to produce, stating that it actually gave him an incredible amount of freedom to manipulate the image, which he found to be liberating. ${ }^{87}$ Scorsese also states that using digital tools made him consider shooting an all-digital movie in the future, acknowledging how the cinematic medium is changing. ${ }^{88}$ The Aviator focuses on the life of Howard Hughes (Leonardo DiCaprio) from approximately 1927-1947, featuring Hughes' careers in aviation and cinema, as well as frank depictions of his obsessive-compulsive disorder. Scorsese deliberately highlights the glamorous aspects of Hughes' life such as attending movie premieres, visiting the dazzling Cocoanut Grove nightclub, and his relationships with various movie stars. Hughes' cinephilia is also emphasized, with several scenes featuring him meticulously watching and editing his films. These images of extravagance and cinematic appreciation appear to be nostalgic representations of the era, and possibly reflective of Scorsese's own feelings of nostalgia for Old Hollywood as well as traditional, celluloid-based filmmaking.

Despite his praise of the digital intermediate and discussion about how cinema is in transition, Scorsese chose to use this new technology to replicate older, photochemical-exclusive styles of cinema, much like Gary Ross did with Pleasantville. This chapter will examine why Scorsese chose to use the digital intermediate to reproduce two- and three-strip Technicolor, and how this recreation allows him to engage in a nostalgia for the Golden Age of Hollywood. First, the use of the digital intermediate in The Aviator will be examined. This will be followed by an examination of the nostalgic representation of Hughes and Hollywood during the period covered by the film. Finally, Scorsese himself will be discussed, as The Aviator may represent his own sense of nostalgia for a certain time period and method of film production, which is displayed

\footnotetext{
${ }^{87}$ Michael Goldman, “Scorsese's Color Homage," Millimeter 33.1 (2005): 22.

${ }^{88}$ ibid 26
} 
through Old Hollywood spectacle and the use of the digital intermediate to recreate photochemical film styles that Scorsese personally enjoys.

\section{“Find Me Some Clouds!": The Aviator and Digital Colour}

The Aviator is notable for its Technicolor aesthetic, which was created using a combination of digital effects and practical special effects originating in old Hollywood. ${ }^{89}$ The film begins with a recreation of two-strip Technicolor, which was used during the 1920s and 1930s. The experimental process yielded interesting results, with blue-gray glass, aqua-coloured skies, and a blue shine on metallic objects. ${ }^{90}$ After Hughes sets a speed record for flying across the United States, the colour transitions into the well-known three-strip Technicolor aesthetic of the 1940s and 1950s, featuring vibrant reds and yellows. As Technicolor was used in many of the Hollywood films released during Howard Hughes' career, director Martin Scorsese wanted the biopic to include these colour palettes. ${ }^{91}$ Cinematographer Robert Richardson and visual effects supervisor Robert Legato used a digital intermediate to recreate the look of two- and three-strip Technicolor, ${ }^{92}$ while using practical effects elsewhere, such as miniature radio-controlled airplanes during flight sequences. ${ }^{93}$

\footnotetext{
${ }^{89}$ Robert Legato, “The Aviator: Visual Effects Overview." Warner Bros. Pictures, accessed February 10, 2013. http://www.aviatorvfx.com/index.php?cmd=frontendOverview\&id=vfx

${ }^{90}$ Goldman 15

${ }^{91}$ John Pavlus, "High Life," American Cinematographer 86, no. 1 (2005): 39.

${ }^{92}$ ibid 39-40.

${ }^{93}$ Legato, http://www.aviatorvfx.com/?cmd=frontendOverview\&id=vfx
} 
One of the challenges of using the digital intermediate to recreate Technicolor aesthetics was creating a program sophisticated enough to efficiently produce the required colour palettes. As the original Technicolor process was the result of "a combination of filtration and dyeing to create colored release prints from a matrix of two or three strips of black-and-white negative," ${ }^{94}$ and the dye-transfer process used in many Technicolor films was permanently decommissioned in $2002,{ }^{95}$ a digital intermediate was necessary to recreate this particular aesthetic. Developing a digital recreation of this process was highly complex:

To create a period Technicolor palette that could be applied consistently and quickly to entire scenes or reels, Richardson worked with visual-effects supervisor (and second-unit director) Rob Legato and Technicolor Digital Intermediates (TDI) senior colorist Stephen Nakamura. Their goal was to take the digital intermediate (DI) to a new level of sophistication via 3-D look-up tables, or LUTs. Designed by Josh Pines, vice president of imaging research and development at TDI, the LUT -a dedicated, high-powered graphics processor that could be slipped into the projector during digital color-correction -- acted like a digital filter, applying a twocolor or three-color look in real time to Cineon scans of The Aviator's camera negative. ${ }^{96}$

Additionally, Richardson explained that since The Aviator was already a visual-effects heavy project, creating a Technicolor aesthetic through the digital intermediate made sense. ${ }^{97}$ To create an accurate look for the film, the production crew watched various two- and three-strip Technicolor films, including rare prints of the two-strip Technicolor films The Toll of the Sea (Chester M. Franklin, 1922), The Black Pirate (Albert Parker, 1926) and three-strip Technicolor short La Cucaracha (Lloyd Corrigan, 1934). ${ }^{98}$ Richardson also opted to use older technology to

\footnotetext{
${ }^{94}$ ibid 39

${ }^{95}$ Goldman 16

${ }^{96}$ Pavlus 39-40

${ }^{97}$ ibid 50

${ }^{98}$ ibid 48-50
} 
achieve the lighting, shadow, and sharpness seen in many older films. During the Hell's Angels premiere sequence, period carbon-arc lamps were used for lighting, as well as period flashbulbs while photographing Hughes. ${ }^{99}$

The film's colour was meant to mimic the evolution of both film technology and Hughes' emotional state, as explained by Richardson:

...Marty [Scorsese] designed a color timeline that influenced every creative department. He wanted the progression from a two-color palette to a three-strip palette to approximate the technological advances of the film industry at that time, but more importantly, he felt it would mirror the characters' emotional evolution. The first act, which covers Hughes's early career in Hollywood, was supposed to have Technicolor's two-color look. With the second act, which begins after Hughes sets a speed record flying across the continental United States [in 1937] and goes with Katharine Hepburn to Connecticut, we transition to that vibrant, three-strip look that most of us associate with the glorious Technicolor years. ${ }^{100}$

Interestingly, Richardson and Legato also mention that three Technicolor transitions were originally planned. A more contemporary colour style was supposed to appear after Hughes almost dies while crashing the XF-11, which tremendously affected Hughes' mental and physical health; it was later dropped after Scorsese missed seeing the Technicolor. ${ }^{101}$ However, costumes and makeup were modified to give the film a more contemporary feel while maintaining the richer skin tones notably seen in three-strip Technicolor. ${ }^{102}$

Though Scorsese and Richardson did want to resuscitate old filmmaking techniques and styles, they recognized that this was not always feasible. Richardson notes that they chose not to recreate period-style camera moves or use the then-standard 1.33:1 aspect ratio, as many modern

\footnotetext{
${ }^{99}$ Pavlus 41-42

100 ibid 48

${ }^{101}$ ibid 48

102 ibid 48
} 
theatres are incapable of projecting using that ratio. ${ }^{103}$ Richardson also mentions the difficulty in using the digital intermediate for colour correction and control, particularly in a film as technically complex as The Aviator. According to him, creating and using the specialized colour palette in a way that made "mental sense" was the greatest challenge, as it affected every department working on the film and specialized colour palettes remain difficult to develop using the digital intermediate. ${ }^{104}$ The results of using the digital intermediate were not perfect, with Richardson noting that the colour, while vivid, "wasn't quite as glorious" as that of an original Technicolor print. ${ }^{105}$ Replicating two-strip Technicolor was especially challenging, as few good quality nitrate prints of films using the technique were available for screening. ${ }^{106}$ There were also issues with greenscreen technology used in the film, as Richardson was new to that particular technology and had trouble with lighting long sequences that used the greenscreen. ${ }^{107}$

Scorsese, Richardson, and Legato made very calculated decisions with colour created by the digital intermediate in The Aviator. Both the two-strip and three-strip Technicolor segments of The Aviator are constructed to prominently display the specific hues that make the movie's Technicolor aesthetic unique. The aesthetic is first apparent during the initial sequence on the Hell's Angels set, when Hughes hires Noah Dietrich (John C. Reilly) to run his tool company. Dietrich meets Hughes on an outdoor set, with vivid turquoise skies and bright red airplanes. The characters' skin has a slight red tint, and it is immediately obvious that certain colours look unnatural, such as the green-blue stripes seen on Hughes' sweater. The aesthetic continues to be

\footnotetext{
103 ibid 40

${ }^{104}$ ibid 46

105 ibid 50

${ }^{106}$ Goldman 16

${ }^{107}$ Pavlus 44-46
} 
foregrounded in later scenes, with Hughes eating blue peas at the Cocoanut Grove nightclub; the nightclub itself completely appears in magenta-based red and cyan tones. Later, after Hughes meets actress Katharine Hepburn (Cate Blanchett), they play golf together on turquoise grass, in a scene likely referencing Follow Thru (Lloyd Corrigan and Lawrence Schwab, 1930), a golf film featuring blue grass. ${ }^{108}$ The final scene before the transition to three-strip Technicolor also accentuates the bipack colour simulation, with Hughes crashing his $\mathrm{H}-1$ racer aircraft after setting a new speed record. Hughes loses control of the aircraft after running out of fuel, landing in a beet field in rural California. The aquamarine plants and dark red juice of the beets destroyed in the crash provide a final, spectacular glimpse at the distinctive colour palette.

The transition to three-strip Technicolor is more understated than the first appearance of the two-strip aesthetic, but it remains well-defined. Three-strip Technicolor is introduced after Hughes' record-breaking flight around the world, shown through altered newsreel footage, with Leonardo DiCaprio digitally spliced into the image. The newsreel footage concludes with a shot of the Empire State Building, which slowly transitions from black and white into three-strip Technicolor, distinguishable from the previously seen two-strip aesthetic as the sky becomes a true blue with no cyan tint. The passage into three-strip Technicolor is further stressed in the following scene in the office of Pan-Am Airways founder Juan Trippe (Alec Baldwin), Hughes' aviation rival. As Trippe watches the newsreel footage of Hughes triumphantly returning from his worldwide flight, the colours in his office become more pronounced. The office walls are various shades of green, and assorted objects in the room appear in shades of blue, both colours which did not appear during the bipack colour sequences. Three-strip colours continue to be

108 Goldman 15 
conspicuously displayed in a red carpet sequence. The full spectrum of colours returns to the image, presented through Katharine Hepburn's yellow dress and the deep, true red carpet, other colours that are previously unseen. After the Technicolor aesthetic is slightly subdued following Hughes' near-fatal XF-11 accident, colours unseen in two-strip Technicolor are still exhibited. The meal Hughes shares with Senator Ralph Owen Brewster (Alan Alda) when discussing the Community Airline Bill can be contrasted with the meal Hughes attempted to consume at the Cocoanut Grove. The vegetables in the former meal are a deep green, and the brook trout is subtly tinted red, whereas the blue peas seen at the Cocoanut Grove appear unnatural. The colours seen in the three-strip sequence are warm and radiant, giving The Aviator the appearance of a classic Technicolor film from the 1940s.

The creation of a digital intermediate that specifically replicates the appearance of Technicolor is technically impressive, and demonstrates how the technology has progressed following the release of Pleasantville. However, the digital intermediate in The Aviator is used to evoke specific feelings nostalgia, as opposed to exploring the various implications of nostalgia as seen in Pleasantville. When combined with the loose retelling of Howard Hughes' life, Scorsese uses the various colour palettes in The Aviator to create a nostalgic portrait of Hollywood grandeur, rather than a factual biopic.

\section{“You Don't Care About Money Because You've Always Had It!”: Mythologizing Hollywood's Past}

The recreation of Technicolor aesthetics in The Aviator serves a very specific purpose in creating a sense of nostalgia for Old Hollywood. By recreating a past aesthetic, Scorsese engages 
in deliberate archaism, which "entails the artist's desire to recreate not only the look and feel of the period in question but to give his artifact the appearance of art from that distant time." 109 Deliberate archaism also "relates to the fact that much nostalgia is evoked by memories of media forms," which eventually results in the creation of "new-old" art, which replicates the style of past works. ${ }^{110}$ The Aviator also deploys various tropes associated with the retro film, which connote pastness without regard to historical accuracy. ${ }^{11}$ The movie received criticism for excessively use of deliberate archaism, with Christine Sprengler noting that it was "faulted for appealing only to film buffs and film historians because it invests more in recreating the look of Hollywood cinema of the 1920s and 1930s than it does in telling us about Howard Hughes or history." 112 The criticism mentioned by Sprengler does draw attention to one of the major issues with The Aviator's narrative, which is its overreliance on nostalgic tropes to create a romanticized portrait of Old Hollywood while simplifying the story of Hughes' life. This section will thus examine how The Aviator uses Howard Hughes' life as a basis for creating nostalgic celebration of Old Hollywood by extensively focusing on the luxurious lifestyles of miscellaneous characters.

Despite his mental illness and financial troubles, in The Aviator Hughes is depicted as living an incredibly glamourous life, with sequences celebrating his opulence and the splendour of Old Hollywood. This reflects another aspect of deliberate archaism, namely that "what is

\footnotetext{
${ }^{109}$ Marc Le Sueur, “Theory Number Five: Anatomy of Nostalgia Films: Heritage and Methods," Journal of Popular Film 6.2 (1977): 194.

110 ibid 194

111 Philip Drake, “"Mortgaged to Music: New Retro Movies in 1990s Hollywood Cinema," in Memory and Popular Film, ed. Paul Grainge (Manchester: Manchester University Press, 2003), 188.

${ }^{112}$ Christine Sprengler, Screening Nostalgia: Populuxe Props and Technicolor Aesthetics in Contemporary American Film (New York: Berghan Books, 2009), 142.
} 
being enacted on the screen is often a form of wish fulfillment expanded to the magnitude of myth." 113 The Aviator attempts to recreate the experience of success in Old Hollywood for the modern spectator. A significant portion of the movie's narrative is devoted to Hughes' grandiose aviation and cinematic endeavours; the entire two-strip Technicolor section focuses on Hughes producing Hell's Angels and setting aviation records. The three-strip portion continues this focus on Hughes' luxurious lifestyle, though his struggles with mental illness and difficulties producing the "Spruce Goose" airplane receive coverage. Though Hughes faces several challenges in his personal life, they are often downplayed in favour of Old Hollywood spectacle. The most notable example of this is Hughes' convalescence after his disastrous XF-11 plane crash. Though Hughes suffered many severe injuries he is only seen recovering in two scenes. In both scenes, Hughes' recovery is not the focal point; he is only unconscious during three shots, early in his hospital stay. More focus is given to Hughes' visitors, plans for continuing his government wartime contract, and the flowers sent by Juan Trippe. Hughes' mental illness receives a similar treatment, with his self-imposed quarantine immediately being contrasted with his strength and eloquence at the Senate War Investigating Committee hearing.

The Aviator also includes several scenes of a nostalgic or overtly cinematic nature, which are often detrimental to the story and the connection to the real Howard Hughes. Some of these scenes feature private moments in Hughes' life, which are likely fictional; Hughes' visit to Katharine Hepburn's family estate falls into this category. The family shares a meal, at which Hughes' deafness and neuroses become overwhelming, causing him to excuse himself early. This is a scene that was probably added to explore Hughes' relationship with Hepburn, and unlikely to

${ }^{113}$ Le Sueur 193 
have been inspired by true events. Additionally, the sense of nostalgia in The Aviator is heightened by omitting references to any contemporaneous news or social issues not directly involving Hughes. The Great Depression receives a single offhanded mention from a radio announcer on the Hell's Angels red carpet; Hughes is shown living a luxurious life throughout the 1930s. World War II is only referenced in connection to Hughes' aircraft construction and use of government funding. This glossing over of social issues reinforces the nostalgic myth that life was easier in past eras, particularly as The Aviator uses Old Hollywood glamour to create a spectacle of nostalgia.

The digital intermediate used in the The Aviator also employs Hughes' wealth to create a specific image of the Roaring 1920s and Old Hollywood glamour. This image is produced through the strategic placement of colour, using contrasting shades to draw attention to the spectacle of life in Hollywood. An early scene features Hughes meeting with studio head Louis B. Mayer (Stanley DeSantis) about borrowing extra cameras to shoot Hell's Angels. The Cocoanut Grove is a shining example of 1920s luxury, with the turquoise and red bipack colour aesthetic accentuating the club's Art Deco decor. All of the club patrons wear clothing that appears with an aqua or coral tint in two-strip Technicolor, and the showgirls wear glittering blue-silver costumes that draw the eye of the spectator. The bipack colour continues to emphasize the glamour of Old Hollywood during the Hell's Angels red carpet sequence. Colourized newsreel footage of the film premiere plays featuring throngs of fans, luxury cars, and premiere attendees. These crowds are coloured in contrasting red and blue tones, as a radio announcer vividly describes the opulence he is witnessing, which greatly emphasizes the spectacle of the premiere. Even personal moments are given a understated, sumptuous 
appearance with bipack colour; Hughes' private flight with Katharine Hepburn features soft peach colours, accentuating the grandeur of an intimate moment.

Three-strip Technicolor is also used to highlight the luxuriousness of the post-Depression era. The aesthetic first appears in Juan Trippe's office, calling attention to his office, which is lavishly decorated with murals appearing in vivid shades of cerulean and green. This is followed by another red carpet sequence, this time celebrating the premiere of The Women (George Cukor, 1939). The sequence prominently features Hepburn wearing a yellow evening gown, while other attendees are also seen wearing lavish colours, such as hot pink and deep violet. These bold colours again highlight the transition into the three-strip aesthetic by noticeably displaying hues that are impossible to create using bipack colour. Three-strip colour also foregrounds luxury outside of the public sphere when Hughes visits the Hepburn family estate in Connecticut. Colours in the sequence consist of verdant green and warm crimson hues; both draw attention to the natural setting of the rural estate as well as the Hepburn family's intellectual passion.

Christine Sprengler notes that The Aviator is a peculiar film, as it "announces its setting as the 1920s to the 1940s yet makes use of the visual strategies inaugurated through cinematic recreations of the [mythical 1950s], ${ }^{114 "}$ the era most celebrated in nostalgia. Nostalgia is thoroughly entrenched in The Aviator, with the narrative and Technicolor aesthetic combining to create a spectacular portrait of Old Hollywood excess. Interestingly, The Aviator also reflects various qualities associated with director Martin Scorsese, as an auteur, as a cinephile, and as someone who engages with nostalgia, giving it an added depth not usually found in pure nostalgia films.

114 Sprengler 139 


\section{Memories of the Auteur: Scorsese's Personal Nostalgia in The Aviator}

The Aviator uses its Technicolor aesthetic and narrative to create a nostalgic depiction of Hollywood between the 1920s and 1940s. It also exhibits narrative and technical qualities associated with Scorsese's other work as an auteur, particularly in terms of preserving the past. Scorsese uses The Aviator to preserve aspects of film history that greatly influenced him as a young spectator while simultaneously mourning the downfall of celluloid. Thus, the final section of this chapter will examine how The Aviator is a product of Scorsese's personal nostalgia and auteurism.

Scorsese has spoken at length about how film influenced his childhood and his own cinematic work as an adult. This influence is incredibly visible in The Aviator, with Scorsese discussing his inspiration in interviews. Scorsese decided to experiment with colour in The Aviator because film colour fascinated him while he was young. He particularly enjoyed how film offered different forms of colour to the audience, ${ }^{115}$ and early two-strip Technicolor processes greatly influenced him because they were so diverse:

Each [technicolor] process was different, and therefore, each film was different. That period of filmmaking and film viewing was formative for me, in a very primal way, and those images remain imprinted in my mind. Since the subject matter of this movie begins with Howard Hughes the filmmaker during this period, I thought it would be interesting to explore adding these colour schemes to [The Aviator]. ${ }^{116}$

Scorsese has previously experimented with deliberate archaism in films such as New York, New York (1977), in which Scorsese recreated the aesthetic of post-World War II New York City,

\footnotetext{
${ }^{115}$ Goldman 15

116 ibid 15-16
} 
though characters behaved in more contemporary ways. ${ }^{117} \mathrm{He}$ also chose to shoot Raging Bull (1980) in black-and-white " as a tribute to Warner Bros films of the 1940s," and "as a protest against the deterioration of colour values." 118 The Aviator is thus Scorsese's way of confronting his anxiety regarding the disappearance of film history, both on a technical and narrative level.

Scorsese managed to recreate and preserve two-strip Technicolor aesthetics through the use of the digital intermediate, a tool the "traditionalist" approached with skepticism. ${ }^{119}$ As The Aviator marked Scorsese's first occasion using digital tools on one of his films, he engaged in the process of remediation:

At one extreme, an older medium is highlighted and represented in digital form without apparent irony or critique....In these cases, the electronic medium is not set in opposition to painting, photography, or printing; instead, the computer is offered as a new means of gaining access to these older materials, as if the content of the older media could simply be poured into the new one. Since the electronic version justifies itself by granting access to the older media, it wants to be transparent. The digital medium wants to erase itself, so that the viewer stands in the same relationship to the content as she would if she were confronting the original medium. Ideally, there should be no difference between the experience of seeing a painting in person and on the computer screen, but this is never so. ${ }^{120}$

The Aviator can be considered an extreme example of remediation. Scorsese highlights

Technicolor by using the digital intermediate, allowing access to a media form which was unknown to many cinematic spectators in the case of two-strip colour. However, the two-strip Technicolor in The Aviator looks very different from celluloid films like The Phantom of the Opera (Rupert Julian, 1925) made using the analogous celluloid technique, with the colour in

\footnotetext{
${ }^{117}$ Pavlus 48

${ }^{118}$ Pam Cook, Screening the Past: Memory and Nostalgia in Cinema (London \& New York: Routledge, 2004), 168.

${ }^{119}$ Goldman 16

120 Jay David Bolter and Richard Grusin, Remediation: Understanding New Media (Cambridge, Mass.: MIT Press, 1999), 45.
} 
The Aviator appearing to be more vivid and less grainy. ${ }^{121}$ Despite the differences between the two colour processes, two-strip Technicolor in The Aviator does engage spectators by educating current and future audiences of "the presence of colour in 1920s and 1930s film," 122 while preserving an "exclusively cinematic" 123 aspect of film history.

In addition to remediating two-strip Technicolor, The Aviator also demonstrates Scorsese's deep respect for history, though he chooses to approach it through a nostalgic lens. Memory, the past, and nostalgia-related themes are common in the narratives of many of his films, indicating that The Aviator can connect with his other works on an auteurist level. These themes greatly impact the actions of his protagonists, and Pam Cook notes that in many of Scorsese's films "the loss of the past is given a tragic dimension, as his flawed, alienated heroes, trapped by history, struggle to establish and maintain their identity." 124 Concepts relating to history appear as major themes in several of Scorsese's films, including the previously mentioned Raging Bull, mobster Henry Hill biopic Goodfellas (1990), Gangs of New York (2002), and Hugo (2011). Hugo, an adaptation of a children's book, can be considered an extension of The Aviator, as both films were created using digital effects and feature nostalgia for a particular era of cinema. Hugo was filmed in 3D, and celebrates filmmaker Georges Méliès as well as early sound cinema. Additionally, Scorsese's interest in history extends to his personal life, as he personally archives his films, ${ }^{125}$ and he feels anxiety about the erosion of the past. ${ }^{126}$

\footnotetext{
${ }^{121}$ Sprengler 148

122 ibid 149

123 ibid 145

${ }^{124}$ Cook 168

125 ibid 174

126 ibid 168
} 
As the portrayal of historical events in The Aviator is greatly influenced by Scorsese's nostalgia for the era, the film appears to be incredibly influenced by something Philip Drake refers to as memorial knowledge. Drake defines memorial knowledge as "....knowledge of the past based upon selective and strategic remembering in the present....made up of a mixture of personal memory and public memories that over time become fused and indistinguishable." 127 The Aviator is an excellent example of this fusion, with Scorsese combining public memories, personal recollections of Hughes, and his own personal memories to create his nostalgic image of Old Hollywood. Scorsese punctuates key moments in the film with archival newsreel footage, acknowledging the medium which helped create public memories during the film's timeframe. Incorporating newsreel footage also attempted to connect the film to reality, as "[spectators] ought to read newsreel footage as documentary evidence and allow its 'authenticity' to inflect [their] consumption of the information it contains." ${ }^{128}$ However, virtually all of the newsreel footage included in the film was manipulated by Scorsese:

The Aviator seems less concerned with exploring (or challenging) the truth value of documentary record than it does with the potential for digitally manufactured deliberate archaic regimes to enable their own kind of access to history. In this film both are equally adept at engaging the past, both are equally mediated, manipulated and malleable and both belong to a set of representational practices of which no one is privileged as more authentic or valid than another. ${ }^{129}$

The alteration of the newsreel footage often consisted of colourization, allowing the footage to match the Technicolor aesthetic used in that particular segment of film. In the case of the newsreel documenting Hughes' 1938 record-breaking worldwide flight, the manipulation was

\footnotetext{
${ }^{127}$ Drake 184

${ }^{128}$ Sprengler 150

${ }^{129}$ ibid 150
} 
more blatant, as the footage was digitally altered to include images of Leonardo DiCaprio in place of the real Howard Hughes. Thus, the manipulation of this footage damages the film's connection to reality, further emphasizing the film's nostalgic position and Scorsese's dedication to his personal memories.

Scorsese's personal memories of cinema greatly influenced sections of The Aviator's narrative. As previously examined, certain scenes appeared to be added simply for the sake of highlighting The Aviator's devotion to nostalgia. In addition to creating an ode to Technicolor with the digital intermediate, Scorsese also inserted scenes which are only meant to reference the cinema while doing little to strengthen the narrative. The best example of this is a scene in which Hughes threatens a paparazzo attempting to purchase scandalous photos of Katharine Hepburn and Spencer Tracy. The scene references several tropes associated with film noir, including lowkey lighting, a secret meeting, and a tense moment between two parties. The film noir elements of the scene were greatly played up, continuing a trend seen throughout The Aviator, with the biographical elements of Hughes' life being overlooked in favour of nostalgic spectacle. Referencing cinematic tropes in key scenes undermines The Aviator's historical accuracy; however, these references demonstrate a clear personal connection to Scorsese and his perception of memorial knowledge. Christine Sprengler notes that the Technicolor aesthetics in The Aviator “....are almost palpable to [Scorsese] and come to mind whenever his thoughts turn to 'Old Hollywood'. They are firmly imprinted on his consciousness and form the basis of 'sense memories' of having watched films from this 'great period' as a child," 130 which is also reflected throughout the narrative of The Aviator. Film references and the use of the digital intermediate

${ }^{130}$ ibid 146 
allow Scorsese to connect his personal nostalgia with technological innovation, giving the superficial nostalgic spectacle a specific purpose.

\section{Conclusion}

While The Aviator is Scorsese's own nostalgic perception of cinema and the 1940s, it also attempts to preserve overlooked aspects of film history by using the digital intermediate. Though it is heavily invested in generating nostalgia for both the audience and Scorsese, The Aviator should also receive credit for the digital intermediate used to recreate two-strip and three-strip Technicolor. Visual effects producer Ron Ames believes the process can be modified and used to emulate other aesthetics that would be otherwise impossible to create. ${ }^{131}$ The Aviator is also the film that caused Scorsese to rethink the use of digital tools for future projects:

The entire art form is changing, so it makes sense to use new tools," Scorsese says. "Films as we know them will no longer be made the same way now that we have the kind of control with digital intermediates and digital rushes. I haven't shot with a digital camera yet - lots of guys know more about it than I do. I will always prefer film. But on the other hand, as I look back [on The Aviator], I realize I made many judgments on this film based solely on digital rushes and digital projection. That has made me start thinking about [shooting digitally). I look forward to the day when I can try a digital camera. I'm sure 1 will shoot an all-digital movie eventually. It's a different tool, and it's about time I tried it. ${ }^{132}$

Thus, The Aviator's importance lies not in its superficial nostalgic narrative, but rather in the technological progress it inspired. The film successfully uses the digital intermediate to present an argument about early film colour by "visually articulating the discourses about colour cinema

\footnotetext{
${ }^{131}$ Goldman 26

132 ibid 26
} 
that circulated during the periods it represents"133 and by using arguments about film colour to reflect current debates regarding digital cinema, as "the early concerns about colour's potential to distract from the narrative or indulge only in visual spectacle are echoed in some of the charges currently being levelled against digital cinema." 134 Though Scorsese's use of history in The Aviator has issues, the importance of his work with the digital intermediate gave filmmakers new tools with which to explore cinema history. This allows historical films to embrace an older aesthetic, engaging the audience in a new cinematic experience and giving filmmakers the opportunity to experiment with older film styles.

\footnotetext{
${ }^{133}$ Sprengler 158

${ }^{134}$ ibid 158
} 


\section{Chapter Three: The Artist}

Following the release of The Aviator (Martin Scorsese, 2004), use of the digital intermediate became commonplace in films released by major Hollywood studios. In 2005, fewer than half of films released by the major studios had been processed using a digital intermediate but the number quickly climbs, with approximately seventy percent of major studio releases using a digital intermediate by $2007 .{ }^{135}$ As digital intermediate use became prevalent, the cost of the technique dropped, with certain processes available for less than $\$ 100,000.136$ Studios discovered that the digital intermediate was extremely cost-effective, as the procedure permitted directors to save on post-production expenses and allowed for the simultaneous production of film and video masters, thus bolstering distribution. ${ }^{137}$

In 2011, two movies which used digital filmmaking techniques and examined themes relating to nostalgia and the cinema were released: Hugo (Martin Scorsese, 2011) and The Artist (Michel Hazanavicius, 2011). These features proved popular with audiences and dominated awards season, each winning five Academy Awards. Hugo, an adaptation of Brian Selznick's 2007 novel The Invention of Hugo Cabret, is Martin Scorsese's first movie to be shot in 3-D via digital capture. ${ }^{138}$ Hugo uses 3-D and digital colour to recreate France during the early 1930s, and the film is a celebration of both early sound cinema and the work of filmmaking pioneer Georges Méliès. The Artist focuses on similar themes, as it explores the transition to synchronous

\footnotetext{
${ }^{135}$ John Belton, “Painting by Numbers: The Digital Intermediate,” Film Quarterly 61.3 (2008): 58.

136 ibid 58

137 Stephen Prince, Digital Visual Effects in Cinema: The Seduction of Reality (New Brunswick, New Jersey: Rutgers University Press, 2012), 76.

${ }^{138}$ Mark Hope-Jones, “Through a Child's Eyes,” American Cinematographer 92, no. 12 (2011): 55-56.
} 
sound films during the late 1920s in Hollywood. Protagonists George Valentin (Jean Dujardin) and Peppy Miller (Bérénice Bejo) provide contrasting experiences with the transition to sound; silent star George's career implodes when he refuses to transition to talkies, while rising star Peppy embraces sound. However, though thematically similar to Hugo, The Artist differs greatly on a technical level, as it uses a digital intermediate, among other techniques, to completely recreate the aesthetic of a 1920s silent melodrama, adding a new dimension to the period film.

The Artist will thus be the focus of this chapter, interpreted as a film that offers a particular reflection on the experiences of the past that the cinema can make available to viewers through processes of both mediation and remediation. The Artist thematises the complexity of technological change in the cinema, emphasising that new technologies can never wholly replace older ones, or completely transform older styles. The use of the digital intermediate and other historical techniques to recreate the aesthetic of silent cinema will first be discussed. This will be followed by an examination of how The Artist examines memory and nostalgia, using Alison Landsberg's concept of "prosthetic memory" as a foundation. Finally, the implications of creating The Artist as a complete remediation of a silent film will be considered, particularly in terms of how the film seeks to educate viewers and celebrate silent cinema.

\section{“Make Your Talking Movies. I'll Make A Great Movie!”: Crafting the Silent Aesthetic}

The Artist was filmed using a 35mm negative and a digital intermediate, the Lustre plugin, to desaturate the image. ${ }^{139}$ In the early stages of the project, director Hazanavicius prepared a

\footnotetext{
${ }^{139}$ Benjamin Bergery, “Silent Splendor,” American Cinematographer 92.12 (2011): 72.
} 
series of silent film screenings for his collaborators at the Cinemathèque. He believed that seeing the films in a theatre was important, as it allowed the crew to become fully immersed in the world of silent cinema. ${ }^{140}$ To recreate the aesthetic of a silent-era film, Hazanavicius and cinematographer Guillaume Schiffman used the digital intermediate as well as other tools and techniques commonly used during that period. The Artist was shot on $35 \mathrm{~mm}$ filmstock, with soft lensing and hard lighting. ${ }^{141}$ Hazanavicius also used older Panavision Super Speed lenses with a $40 \mathrm{~mm}$ focal length, which was common for the era; certain shots, such as close-ups, used 50 $\mathrm{mm}$ and $75 \mathrm{~mm}$ lenses as needed. ${ }^{142}$ Additionally, Panavision optical engineer Dan Sasaki created custom attachments which screwed into the lenses to soften images in certain scenes. ${ }^{143}$ Cinematographer Schiffman's work was key to recreating the 1920s aesthetic in The Artist, which he accomplished through lighting and desaturation. As soft lighting is common in modern cinematography, Schiffman's hard lighting distinguished The Artist from modern films. ${ }^{144}$ Schiffman also used light to create visual themes for characters George Valentin and Peppy Miller. George's duality was reflected with a prominent shadow always appearing in the frame with him while Peppy had a luminous aura following her created using soft light. ${ }^{145}$ Schiffman also created a monochrome palette with reduced contrast, resulting in muted whites and gradation of rich grey tones. ${ }^{146}$ Schiffman explained that "'Black-and-white' without gray is

\footnotetext{
140 ibid 68

141 ibid 72

142 ibid 72

${ }^{143}$ ibid 72

144 ibid 76

145 ibid 69

${ }^{146}$ ibid 70
} 
too flashy,"” and that Hazanavicius encouraged him to create a large range of grey tones. ${ }^{147}$ Schiffman worked with colourist Richard Deusy to create the digital intermediate, eventually using the Lustre plug-in to desaturate the dailies; digitization of The Artist was a necessity as dailies were transmitted from the set via the internet. ${ }^{148}$

Hazanavicius also diligently worked to ensure that The Artist accurately reflected the aesthetic of silent cinema and his personal vision of the film. He expanded on Schiffman's lighting themes and created another visual theme for the protagonists which charted the journey of their success. ${ }^{149}$ George and Peppy contrast significantly when they are at the peak of their careers, with George wearing a black tuxedo at the beginning of the movie, while Peppy is seen in a white dress after she finds success as an actress. As George struggles after talkies become popular, his palette largely consists of grey tones. ${ }^{150}$ Hazanavicius also chose to shoot using the 1.33:1 aspect ratio, which was also common during the $1920 \mathrm{~s}$. He prefers shooting in 1.33:1, as he believes it allows the actors to maintain a constant screen presence, particularly in full-body shots. ${ }^{151}$

Unlike Pleasantville and The Aviator, the colour manipulation created by the digital intermediate in The Artist is not immediately obvious, nor is it the primary method used to remediate silent film. As discussed in the first chapter, Pleasantville features two sequences of a character's appearance being changed via different colours. These sequences highlight the use of the digital intermediate to manipulate the colour used in individual portions of the image,

\footnotetext{
147 ibid 70

148 ibid 72

149 ibid 70

${ }^{150}$ ibid 70

${ }^{151}$ ibid 74
} 
something that was difficult without digital technology. Additionally, colour manipulation in Pleasantville is consistently present, with the film featuring three immediately distinguishable colour palettes: standard 1990s colour, black and white, and 1950s Technicolor. The Aviator also places a great emphasis on its digital colour manipulation. The first portion of the film features a two-strip Technicolor aesthetic, which primarily consists of various red, cyan, and peach shades. The two-strip aesthetic is immediately recognizable as a manipulation, as certain colours are virtually impossible to create using bipack colour, such as green and yellow. Thus, objects normally appearing in those colours appear in colours that more closely resemble cyan or red, such as the blue grass seen when Howard Hughes and Katharine Hepburn golf together. The Aviator later transitions to a three-strip Technicolor aesthetic, which is more familiar for audiences. This is still recognizable as a manipulation, as the colour is incredibly oversaturated, with lush, vibrant tones dominating the image. In contrast, The Artist does not feature any scenes deliberately highlighting the abilities of the digital intermediate; while Hazanavicius and Schiffman used a digital intermediate to create a specific colour palette for The Artist, as crew members working on Pleasantville and The Aviator did, this colour palette is not the sole method used to recreate the aesthetic of a silent film.

In his American Cinematographer interview, Hazanavicius outlines several historical or analog techniques he and crew members incorporated into The Artist, which are ultimately more important to constructing the film's remediation of silent cinema than the digital intermediate. Some of these techniques are immediately perceptible during the first scene of The Artist. After the complete list of credits is displayed, an intertitle appears, establishing the 1927 setting. An iris shot follows, revealing a man, portrayed by George, being electrocuted and commanded to 
speak, as explained through another intertitle; it is a film-within-a-film, and George is an actor attending the premiere of the film. Superimposition, a special effects technique common during the silent era, is also used during a montage sequence focusing on the production of Tears of Love, George's self-financed silent feature. The superimpositions begin as images of lights and George signing cheques are layered above images of George working. The technique is used to create several striking images during this montage, including a shot of George directing actors on set superimposed over the film reels of a camera, and an image of George typing script revisions superimposed over another on-set acting shot. Superimposition is also used in a shot toward the film's conclusion. As George sits in his burned apartment, images of mouths speaking to him appear on either side of his head. These mouths are symbolic of George's refusal to transition into sound films, and George's pained facial expressions imply that they are taunting him for refusing to adapt to change. Hazanavicius also uses several offscreen techniques to ensure that The Artist resembled a 1920s silent film. He insisted on shooting The Artist at 22 frames per second, which gave the film a melodramatic feeling, since the performers had to overact or rely exclusively on pantomime. ${ }^{152}$ The previously mentioned $1.33: 1$ aspect ratio also ensured that The Artist appeared to be authentic, as other aspect ratios were uncommon until the introduction of the widescreen format in the 1950s.

All of these filmmaking techniques were originally practiced with celluloid, and were commonly used throughout the silent period. This further distinguishes The Artist from previous movies using the digital intermediate for remediation, as Hazanavicius relies on analog techniques to recreate 1920s Hollywood cinema. Not only does The Artist place little importance

152 Bergery 72 
on the colour manipulation created by the digital intermediate, it primarily crafts its remediation using non-digital techniques. This demonstrates a growing familiarity with the digital intermediate, and how its has evolved. The digital intermediate is no longer a fad technology which needs to be emphasized when used, like in Pleasantville and The Aviator. The Artist demonstrates how the technology can now simply be one method of recreating a historical aesthetic, and how its use is no longer the defining characteristic of a feature.

However, though Hazanavicius chooses not to emphasize the use of the digital intermediate in The Artist's narrative, he instead chooses a different method of highlighting the remediation present in the film by focusing on sound. The Artist focuses more on sound than on visuals to emphasize remediation, by using both the score and the brief instances of synchronized sound throughout the film. During the opening premiere sequence, the lack of diegetic sound and visually engaging performances from the actors confirm that the entire feature will be silent. As George is watching the premiere of his latest film from backstage, no diegetic sound is heard throughout the sequence. This is confirmed when George exchanges unheard pleasantries with his costar Constance (Missi Pyle), studio head Al Zimmer (John Goodman), and various crew members. As the screening concludes, everything falls silent while George waits for an audience reaction. His jovial expression implies that the film is well-received, and images of the audience appear onscreen before the non-diegetic score resumes, confirming that the entire film will be silent.

Hazanavicius builds on this sequence, using the score to create a close relationship with the images seen onscreen. The score follows the onscreen action throughout The Artist, using silence, tempo, and tone changes to create a connection with the visuals. During the opening 
film-within-a-film sequence, the score sounds like that of a genuine 1920s melodrama, both indicating the presence of remediation and creating onscreen tension as George's character escapes from his captors. After the film screening concludes, the score transitions into a jazzy, upbeat tune, celebrating the success of George's film while further reflecting the depicted time period. Silence creates tension during key moments, particularly during the aforementioned waiting for applause after the film premiere. A brief moment of silence is also used to highlight an awkward moment as George speaks to the press following the premiere. Peppy, waiting for a glimpse of George in the crowd outside the theatre, drops her wallet. While attempting to retrieve it, she trips and accidentally bumps into George, startling everyone. The score gradually decreases in tempo and fades out as everyone nervously waits for George's reaction. When George eventually laughs and starts playing up the situation for the camera, the upbeat jazz score recommences, and continues until the conclusion of the sequence.

The score also reflects darker moments in The Artist as George's career falters. Melancholy piano plays as George details his losses in the 1929 stock market crash to Clifton, adding tension as George realizes he will be ruined if is self-funded silent film project, Tears of Love, is not a success. This somber music continues as Tears of Love, fails at the box office. Deep string instruments emphasize George's inner turmoil after his wife leaves and he turns to alcohol to cope. Xylophone and percussion music is heard when a despondent George is so drunk that he begins hallucinating his character from Tears of Love, adding a darkly comic layer to the sequence. Melodramatic music comparable to the score of George's film in the opening sequence is heard at later points in the film, when George experiences some serious challenges. This music creates tension as George pulls his old films from their canisters in a rage, 
inadvertently starting a fire when the film is exposed to the heat of his projector. The exciting music continues as his Dog (Uggie) runs to find help, and the music takes on a more triumphant tone as George is rescued. Music with a similar melodramatic tone also plays as George returns to his burned apartment and attempts suicide before Peppy rushes to stop him. This time, the music slowly swells to a crescendo as Hazanavicius intercuts between George examining his apartment while handling his gun and Peppy frantically driving to the apartment.

Hazanavicius' successful creation of this strong connection between the onscreen image and the film's score also results in the creation of two powerful sequences utilizing synchronized sound. These sequences are the most obvious example of Hazanavicius increasingly relying on sound over visuals to remediate silent cinema. The first sequence begins when studio head Al Zimmer screens a sound test for an adaptation of Romeo and Juliet. George laughs and immediately dismisses the talking picture as a novelty, and he refuses to work in the medium. Soon after the screening, George returns to his dressing room, preparing for another day on set. As George sets down a glass of water, he notices that it creates a sound as he places it on his dressing table. Surprised, he continues to move the glass and other items in his dressing room, all of which make noise. George tries to speak, but no sound escapes his mouth. He begins to hear ambient noises, is startled by an unknown rumbling object outside his dressing room, and he eventually trips over a chair as his dog begins to bark. Overwhelmed by the various sounds, George attempts to scream and stumbles out of his dressing room to see a single chorus girl laughing. As George is increasingly agitated, other chorus girls join her, with their laughter becoming louder. After they disappear, George sees a single leaf blowing in the breeze of the now deserted studio, which creates the sound of an explosion as it lands, causing George to 
scream once again. It is revealed that the sequence is a dream, and George wakes from his nightmare to complete silence; even the non-diegetic score ceases as he wakes and exits the bedroom.

The second sequence featuring synchronized sound is grounded within the film's reality. After Peppy successfully halts George's suicide attempt, he laments that he will never be able to perform a speaking role in a film. This gives Peppy an idea, resulting in The Artist's final synchronized sound sequence: a tap dance routine performed by Peppy and George. The taps on their shoes are audible throughout the sequence, as is their heavy breathing at the conclusion of the routine. Voices are also heard, including the director yelling "Cut," when the sequence has concluded, and Al Zimmer expressing his approval. Al also requests one more take, and George replies "With pleasure!," revealing a thick French accent, the implied reason he originally refused to work with synchronized sound.

The synchronized sound sequences immediately indicate that The Artist is a modern interpretation of 1920s silent cinema. Synchronized sound is a cinematic technique that was quite rare during the time period depicted in the film, which is reinforced through the film's plot. Including these synchronized sound sequences means that Hazanavicius is openly displaying his employment of remediation in a manner which is blatantly perceptible to the viewer. The previously discussed remediations seen in Pleasantville and The Aviator may have been ignored or not perceived by audiences without an intimate knowledge of the digital intermediate used to create the remediated onscreen images. However, the synchronized sound used in The Artist is immediately detectable to viewers, and the sequence is jolting after watching approximately 30 minutes of silent material, particularly material featuring a deliberately crafted score and images 
intended to create a supposedly authentic 1920s melodrama. While these sequences demonstrate that Hazanavicius is embracing The Artist's status as a remediation, they also allow for an older medium to be more accessible to a modern audience. As The Artist is remediating a medium often considered to be "boring" by current viewers, openly displaying the remediation is of great importance as it prevents viewers from losing interest in the film, something which is of lesser concern with a synchronized sound film.

The Artist, like the other films discussed in this thesis, remediates an older form of cinema, but it is distinguishable from other films which use a digital intermediate to recreate older film styles for two main reasons. First, the digital intermediate is not the primary method used to recreate the silent film aesthetic, as Hazanavicius and Schiffman used many historical or analog techniques that were ultimately more important than the digital intermediate to ensure that The Artist resembled an authentic silent melodrama. This indicates that the digital intermediate is now commonplace technology, and refraining from blatantly demonstrating its use confirms that the digital intermediate is no longer a novelty. Additionally, The Artist does not rely on digital colour manipulation to demonstrate its remediation of silent film to the audience; Hazanavicius instead uses sound for this purpose. By including a memorable score that thoroughly connects with the onscreen images and select sequences using synchronized sound, Hazanavicius both openly exhibits the remediation seen in The Artist and ensures that contemporary audiences remain interested. 


\section{"You and I Belong to Another Era, George.": The Artist and Nostalgia}

Another contrast between the other films examined in this thesis and The Artist concerns the film's treatment of nostalgia. Unlike Pleasantville, The Artist does not directly address themes relating to nostalgia in the narrative. It also does not create a wholly nostalgic portrait of life during the 1920s, as The Aviator did with the 1920s-1940s. Instead, The Artist strives to create a more historically accurate depiction of life in Hollywood during the late 1920s and early 1930s, accomplished through an exploration of the difficulties many silent film actors faced with the introduction of sound films. The Artist does use certain tropes found in nostalgia films, and it does minimize some less pleasant realities of life during the 1920s. However, though it is not explicitly a nostalgia film, The Artist does examine issues relating to memory and progress, particularly through George, who refuses to embrace talkies.

The Artist presents a generally positive view of the 1920s without completely indulging in nostalgia. Hollywood during the 1920 s is presented as glamourous and prosperous, with employment easily found and a comfortable standard of living. While Peppy easily finds work as an actress and eventually becomes a successful leading lady, this is treated as an extraordinary, unusual situation. Before she begins working in the film industry, Peppy is shown to be an average young woman, and she is surrounded by extras and struggling actors while receiving her first job. George's success is also atypical, and shown to be the result of hard work, though he appears to be egotistical, drawing the ire of his costar Constance and his wife Doris (Penelope Ann Miller). The positive portrayal of the 1920s in The Artist is not explicitly nostalgic, but it is 
constructed using various Hollywood tropes, such Peppy's unlikely discovery and subsequent successful career.

The Artist does not completely ignore the difficulties of life during the 1920s, and the film arguably focuses more on these struggles than on the success of various characters. Most notably, the film explores the difficulties actors encountered during the transition to synchronized sound and the fallout of the 1929 stock market crash which triggered the Great Depression. George creates a self-funded silent film, Tears of Love, after he refuses to work with synchronized sound. Tears of Love is a failure, due to the film opening shortly before the 1929 stock market crash and on the same day as Peppy's latest talkie, The Beauty Spot. Mass audiences are presented as only being concerned with the latest talkie trend, and after George loses more money during the market crash he is bankrupted. However, unlike Pleasantville and other nostalgia films, The Artist never depicts the 1920s as superior to other time periods. While the more overtly nostalgic Pleasantville creates an explicit divide between the 1950s and 1990s during its first sequences, The Artist does not present a comparison between the late 1920s and any other time period.

Though The Artist does recognize issues faced during life during the 1920s, it also glosses over other unpleasant aspects of this time period. Racism and sexism are not explicitly discussed, and Peppy does not appear to experience any sexism or harassment while working. Though George is affected by it, other effects of the 1929 stock market crash and the Great Depression, such as widespread poverty and unemployment, are not acknowledged. Additionally, George's career renaissance is not something that other silent actors would have experienced; many silent film stars were unable to work when sound films became popular. Their careers 
greatly suffered or were ended permanently, and some foreign actors in George's position returned home to continue their careers in their native countries, like German actor Emil Jannings. This minimizing of serious issues is the closest similarity The Artist has with other nostalgia films, and the closest it comes to engaging in pure nostalgia.

While The Artist does not create a nostalgic longing for the viewer to return to the 1920 s, it does seek to create a connection between history, memory, and the audience. This can be best understood by examining Alison Landsberg's concept of "prosthetic memory." Landsberg uses the term prosthetic memory to refer to "...the commodification of memories through history films, television, museums and the Internet threatens to construct pasts that are privately satisfying rather than publicly useful." 153 Landsberg explains that these memories "bridge the temporal chasms that separate individuals from the meaningful and potentially interpellative events of the past," which means that spectators are now able "to have an intimate relationship to memories of events through which one did not live." 154 These memories are distinct from collective memory, which "tend to be geographically specific and which serve to reinforce and naturalise a group's identity,"155; prosthetic memories are "not the property of a single group," and they allow for the "possibility for collective horizons of experience" while "pav[ing] the way for unexpected political alliances." 156 Landsberg's choice of the term "prosthetic" is deliberate, highlighting both the falseness and positive qualities associated with these memories:

\footnotetext{
153 Alison Landsberg, "Prosthetic Memory: the ethics and politics of memory in an age of mass culture," in Memory and Popular Film, ed. Paul Grainge (Manchester: Manchester University Press, 2003), 145.

154 ibid 148

155 ibid 149

156 ibid 149
} 
I call these memories 'prosthetic memories' for four reasons. First, they are not 'authentic' or natural, but rather are derived from engagement with mediated representations (seeing a film, visiting a museum, watching a television show, using a CD-ROM). Second, like an artificial limb, these memories are actually worn on the body; these are sensuous memories produced by an experience of mass mediated representations. And like an artificial limb, these memories often mark a trauma. Third, calling them 'prosthetic' signals their interchangeability and exchangeability and underscores their commodified form. In this sense, I agree with those who have rejected the 'culture industry' model in which mass culture is seen solely as a site of domination and deception....Finally, I call these memories prosthetic to underscore their usefulness; because they feel real they help to condition how an individual thinks about the world, and might be instrumental in generating empathy and articulating an ethical relation to the other. ${ }^{157}$

Landsberg explains that prosthetic memories are highly commodified and mediated, which is why they are so significant. Commodification "is precisely what makes images and narrative widely available, available to people who live in different places, come from different backgrounds, from different races and from different classes," 158 which creates a "sensuous engagement with the past" and allows for the mediation of collective identity, expanding memory beyond that of individual subjectivity. ${ }^{159}$ Commodification of the past through prosthetic memory forges new interpersonal connections and demonstrates the power cinema has in affecting the perception of the audience. These commodified memories are "not memories of events we lived through," but through cinematic identification "they become a part of our archive of memory." 160 This enables spectators to briefly "see through different eyes" and to

\footnotetext{
157 ibid 149-150

158 ibid 150

159 ibid 150

${ }^{160}$ ibid 150
} 
"think beyond [their] social position," which enables them to "remember" the specific event being depicted, as well as broader historical context. ${ }^{161}$

Commodification is how The Artist generates a connection between modern spectators and the 1920s. Modern spectators, who are generally uninformed about the 1920s, can connect with the era of silent film on a more emotional level by empathizing with protagonist George. Spectators are able to experience aspects of the historical events depicted in the film, such as the 1929 Black Friday stock market crash, through George. This personal connection creates new "memories," allowing them to "remember" these events despite not experiencing them outside of the film. Additionally, as nobody involved with the production of The Artist was alive during the era depicted in the film, Hazanavicius and his crew had to rely on mediated representations of the late 1920 s to recreate the time period. This means that the production crew manufactured prosthetic memories of their own while creating the film; thus, The Artist is completely entrenched in prosthetic memories. While The Artist maintains a stronger connection to history and the actual historical reality of 1920s than the other nostalgia films discussed in this thesis, it still presents some elements of nostalgia.

\section{“You've Been Stupid! You've Been Proud!”: Digitization and Restorative Nostalgia}

The Artist is a complete remediation of a silent film, and while it is certainly comparable to the films previously discussed in this thesis, it remediates the silent film and engages with nostalgia in a very different manner than Pleasantville or The Aviator. Instead of focusing on its

${ }^{161}$ ibid 150 
digital intermediate to create this remediation, The Artist uses historical filmmaking techniques researched by Hazanavicius and Schiffman to recreate the silent film aesthetic, while also using sound to distinguish itself from genuine silent films. The Artist also engages with the memory of spectators through the creation of new prosthetic memories, as opposed to reliving older memories through nostalgia. This is necessary, as contemporary spectators likely would not have experienced the late 1920s firsthand, and thus they are unable to engage in nostalgia for that period. While many viewers of Pleasantville would not have experienced 1950s television directly, the programs, as the film shows, have been re-broadcast many times since their original airing. Fewer would have seen older silent films as often. This results in The Artist being more historically inclined than Pleasantville and The Aviator, though it does employ certain tropes associated with nostalgia films. Though the remediation and engagement with memory presented in The Artist differs from that which is seen in earlier films, the reasoning behind this choice of remediation remains similar. The Artist completely remediates silent film for two main reasons: to celebrate silent film while simultaneously educating the audience, and as a possible warning concerning attitudes surrounding the digital shift.

The Artist celebrates the medium of silent cinema in a manner than can be considered a form of nostalgia. Its complete remediation of silent cinema creates a sense of "restorative nostalgia," a term discussed by Marc Le Sueur. Le Sueur notes that there are two main categories of nostalgia: "restorative" nostalgia, and the well-known "melancholic" nostalgia, the wistful longing and romanticization of the past. ${ }^{162}$ "Restorative" nostalgia is possibly the original form

\footnotetext{
162 Marc Le Sueur, “Theory Number Five: Anatomy of Nostalgia Films: Heritage and Methods," Journal of Popular Film 6.2 (1977): 188-189.
} 
of nostalgia, emerging from the Italian Renaissance. ${ }^{163}$ Renaissance thinkers used restorative nostalgia in a "positive, creative" form, as a "forceful guide" to structuring life during the fifteenth and sixteenth centuries. ${ }^{164}$ Ancient Rome and Antiquity eventually "became a corrective influence, enabling the Renaissance to avoid the unrestrained barbarism of the Middle Ages and in particular the Gothic style," and the time periods were "used as an historical beacon to revitalize and discipline in Renaissance art and thought." ${ }^{165}$ Restorative nostalgia declined during the eighteenth century, with the more escapist melancholic nostalgia becoming more prevalent as interest in the decline of Antiquity increased. ${ }^{166}$

The Artist uses restorative nostalgia to revitalize modern film by looking back to silent film, and considering the contemporary transition the digital in relation to the earlier transition to sound. Hazanavicius appears to view silent film as a "corrective influence" on the modern medium, which is increasingly shaped by digital tools. This influence is seen in the great attention to detail regarding the authenticity of the filmmaking practices of the 1920s and Hazanavicius' various references to the works of influential silent film directors, including F.W. Murnau, King Vidor, and Charles Chaplin. ${ }^{167}$ These filmmaking practices and cinematic influences resulted in several of the film's more visually interesting shots and sequences, such as reflecting George and Peppy's respective career trajectories based on their respective lower and higher positions on a staircase; this is also an excellent example of Schiffman's lighting motif, as he brightly illuminates Peppy as she ascends in her career. Another sequence features George and

\footnotetext{
163 ibid 188

164 ibid 188

165 ibid 188

${ }^{166}$ ibid 188

${ }^{167}$ Bergery 77
} 
Peppy separated by a wall, as Peppy loudly denounces silent film in an interview; the two are placed on opposite sides of history. George is also seen out of focus during close-up shots of Peppy speaking, representing Peppy's obliviousness to the hurtful, dismissive tone of her remarks. A later shot, taken at an oblique angle, features a despondent George staring into space while drinking. The camera rotates to reveal that George is looking into a mirror, and he pours his drink on his reflection, blurring the image. All of these shots could have appeared in a silent film originally produced during the 1920s and Hazanavicius gives a certain degree of power back to the image. Engaging in restorative nostalgia demonstrates the pure power of the image to modern audiences, and also proves that innovation in an older medium remains possible.

Using silent film as a "corrective influence" also reflects the persistence of the photographic realism as the ideal form of the film image; D.N Rodowick notes that this is a way of warding off future shock. ${ }^{168}$ The restorative nostalgia displayed in The Artist also couples with the importance of remediation to the film. According to Jay David Bolter and Richard Grusin, one of the keys to understanding digital visual media is by examining how they "honor, rival, and revise" other visual media, particularly "linear-perspective painting, photography, film, television, and print." ${ }^{169}$ As no current media work in isolation from other media, Bolter and Grusin note that the distinctiveness of new and digital media "comes from the particular ways in which they refashion older media and the ways in which older media refashion themselves to answer the challenges of new media," 170 or how these new media forms remediate older forms.

\footnotetext{
${ }^{168}$ D.N. Rodowick, The Virtual Life of Film (Cambridge, Mass.: Harvard University Press, 2007), 179. 169 Jay David Bolter and Richard Grusin, Remediation: Understanding New Media (Cambridge, Mass.: MIT Press, 1999), 15.

${ }^{170}$ ibid 15
} 
While there are many forms of remediation, The Artist is remediating silent cinema in a very specific way:

At one extreme, an older medium is highlighted and represented in digital form without apparent irony or critique....In these cases, the electronic medium is not set in opposition to painting, photography, or printing; instead, the computer is offered as a new means of gaining access to these older materials, as if the content of the older media could simply be poured into the new one. Since the electronic version justifies itself by granting access to the older media, it wants to be transparent. The digital medium wants to erase itself, so that the viewer stands in the same relationship to the content as she would if she were confronting the original medium. ${ }^{171}$

The Artist does not provide an ironic nor a critical interpretation of silent cinema through its remediation, instead providing modern audiences with an almost authentic silent cinema experience. The brief sequences featuring synchronized sound are an exception to this, but those sequences are not intended to criticize silent cinema. The Artist also examines another aspect of remediation, namely the continued dependence on older media:

Finally, the new medium can remediate by trying to absorb the older medium entirely, so that the discontinuities between the two are minimized. The very act of remediation, however, ensures that the older medium cannot be entirely effaced; the new medium remains dependent on the older one in acknowledged or unacknowledged ways. ${ }^{172}$

The Artist examines how synchronized sound cinema remediated silent cinema by completely absorbing it; however, sound cinema continues to rely on silent cinema. Many of the basic principles of filmmaking were established during the silent era, and references to silent films remain prevalent. The Artist both demonstrates and investigates this reliance by completely

\footnotetext{
${ }^{171}$ ibid 45

172 ibid 47
} 
remediating silent cinema while presenting a narrative that examines how synchronized sound cinema first remediated silent cinema.

In addition to remediation, technological anxiety is explicitly depicted in The Artist, and the character of George is used to thoroughly examine the issue. George immediately dismisses sound cinema after his first introduction to the new technology, believing it to be a temporary fad. George's rejection of working with synchronized sound is immediately followed by the first of two synchronized sound sequences in The Artist. This sequence effectively introduces the viewer to George's confusion, fear, and anxiety toward new technology. His fear is made obvious by his failed attempts to speak throughout the sequence, as well as the chorus girls who laugh mockingly at him. When objects in his dressing room begin creating sound, George is confused, and he skeptically handles various objects in an attempt to ascertain why and how this sound exists. This combination of confusion and fear reveals that George is experiencing some anxiety toward the new synchronized sound technology, which is reinforced when George concludes his nightmare by screaming as the feather lands and creates the sound of an explosion. George's anxiety rises from his fear that he will be left behind with the advent of synchronized sound, ruining his career, as well as his confusion and skepticism toward the new technology. This dream sequence marks the beginning of George's downfall, as his anxiety-driven vision of being forgotten becomes reality when his acting career eventually fails. Though his reasoning behind rejecting new technology is unclear until the film's conclusion, George's anxiety and negative attitude concerning synchronized sound is typical of reactions to new media technologies, 
particularly mirroring negative critical reactions toward digital cinematic technologies, such as Anne Friedberg's belief that rapidly changing technology cannot be theorized. ${ }^{173}$

The most important intersection between George's characterization and technology is that George himself becomes remediated by the conclusion of the film. George is a highly successful silent film star who is then thought to be obsolete when synchronized sound technology is introduced to his studio. Though Peppy, who has immensely benefitted from the rise of synchronized sound, denounces silent cinema in an interview, she rethinks her position after George overhears her remarks. Peppy realizes her error in dismissing older technology, and repeatedly attempts to help George when she realizes his value. After a period of time in which he struggles with being "useless," George receives help from Peppy, who finally introduces him to the world of synchronized sound. Peppy remediates George into a musical star, allowing him to translate his physical acting skills developed during his time working in silent film to a new form of media. Peppy recognizing that George's skills can translate well to sound cinema reflects how new media forms are continually reliant on old media. This aspect of remediation is referenced throughout The Artist, and also intersects with the film's treatment of memory. Ignoring both the past and the future can be harmful, and both must be acknowledged, as Peppy and George realized.

The appearance of a film that both examines remediation and remediates an older form of media during the height of film's digital shift is not a coincidence. Hazanavicius uses the narrative of The Artist to argue in favour of the continued importance of photochemical and digital cinema. Digital cinema is forever joined to photochemical cinema, and using digital

\footnotetext{
173 Anne Friedberg, "The End of Cinema: Multimedia and Technological Change," in The Film Theory Reader: Debates and Arguments, ed. Marc Furstenau (London and New York: Routledge, 2010), 278.
} 
production techniques does not immediately destroy analog film. Celluloid cinema also benefits from the proliferation of the digitization; the digital intermediate can be used to rapidly transform images shot on celluloid. Hazanavicius thus uses The Artist to argue for a balance in the approach to digital cinema, demonstrating through George Valentin that old media are never fully obsolete.

\section{Conclusion}

In The Artist, director Michel Hazanavicius uses remediation to explore the concept remediation itself, and demonstrates that old media will never be fully superseded by newer media forms. While his remediation directly replicates silent cinema, it does so in a different fashion than older films using the same techniques. Hazanavicius focuses more on sound to create his remediation, relying on an expressive score and two synchronized sound sequences to indicate that The Artist is not an authentic 1920s film. The digital intermediate is less important, showing how its use has evolved and it can no longer be considered a gimmick. While The Artist focuses on history and memory, there is very little focus on nostalgia. Some unpleasant aspects of the late 1920s are downplayed, but overall the film attempts to create a realistic portrait of the era. Remediation is a major aspect of the film's narrative, as George and Peppy are used to explore issues with old and new media respectively, culminating in George himself being remediated. The Artist is an example of how digital technology can subtly alter film images, as well as how a film can examine current issues in a historical setting. 


\section{Thesis Conclusion}

The purpose of this thesis is to examine why certain filmmakers use the digital intermediate to recreate past film styles, and how this may reflect an uncertainty regarding digital cinema. The films examined in this thesis show a clear evolution of both digital intermediate technology and how filmmakers incorporate this technology into their practice. As the technology behind the digital intermediate has developed and become common in major filmmaking productions, its use is now virtually undetectable. While the digital intermediate progressed, so did the various methods filmmakers used to engage with nostalgia and memory.

The digital intermediate was used to create a blatant display of colour easily detectable by audiences in Pleasantville, the first Hollywood film to use the technology. After a few years of development, it was used to create the subtle, yet noticeable appearance of Technicolor seen in The Aviator. Finally, the digital intermediate became barely noticeable, recreating a typical monochrome 1920s Hollywood film in The Artist. This progression reflects a growing familiarity and acceptance with the technology, as its status as a gimmick is increasingly downplayed. Each of the films discussed in this thesis employed the digital intermediate in differing ways, which also extended to the films' exploration of nostalgia and memory. Nostalgia received direct treatment in Pleasantville, with characters explicitly discussing the theme and rejecting a complete engagement with nostalgia. The Aviator provided director Martin Scorsese with an opportunity to engage in a personal form of nostalgia, as he depicted a romanticized, heavily Hollywood-influenced version of the interwar era in the United States. The Artist eschewed an 
overt connection to nostalgia in favour of examining the late 1920s from a more historical perspective, though it does downplay certain unsavoury aspects of life during that era.

The intersection of digital cinema and nostalgia brings us back to the concept of remediation, and how these films remediate previous media. Using digital tools to remediate analog film styles demonstrates that digital cinema is not necessarily the downfall of the medium. This also reflects the tendency of remediating an old medium as a new medium is introduced, or a new medium attempting to completely absorb an old medium, minimizing disconnections between the two. ${ }^{174}$ The differences in the appearance of the digital intermediate between the release of Pleasantville and The Artist also reflect how the film medium is incorporating digital tools to create images that look as "natural" as possible, ${ }^{175}$ which The Artist achieved with its subtle colour correction. However, these remediations also demonstrate the capabilities of the digital intermediate. Filmmakers can use the digital intermediate to manipulate the image in any number of ways, allowing them the possibility of transitioning away from the photographic ideal. More stylized aesthetics can easily be created, as demonstrated by Scorsese's bipack colour aesthetic in The Aviator, and these aesthetics can easily be disconnected from a "realistic" appearance.

The continual remediation of older film styles also indicates that the older, analog film medium remains greatly influential on digital cinema. Remediation can happen within a single medium, such as a new film "borrowing" or refashioning an older film. ${ }^{176}$ Though critics often consider analog and digital cinema to be distinct media, this refashioning continues and is seen in

\footnotetext{
174 Jay David Bolter and Richard Grusin, Remediation: Understanding New Media (Cambridge, Mass.: MIT Press, 1999), 47.

175 ibid 48

${ }^{176}$ ibid 49
} 
each of the films examined here, particularly The Artist. The Artist is a complete remediation of silent cinema, and it successfully refashions that medium into a form that is more accessible for contemporary audiences. Coupled with the use of the digital intermediate, this refashioning means that filmmakers can accurately recreate a silent film. Looking to older film styles and integrating digital tools in the filmmaking process can allow filmmakers to experiment with old media formats that may have previously been dismissed.

Ultimately, the combination of digital tools and remediating analog film aesthetics demonstrates the many nuances of digital film technology. While digital film tools may be unable to completely replace aspects of photochemical film production, they allow filmmakers many opportunities to experiment with older film styles. Using digital tools to recreate analog film aesthetics also proves that issues with digital cinema cannot always be reduced to a simple analog versus digital debate. Anne Friedberg was apprehensive toward rapidly changing digital technologies, believing they could not be adequately theorized, ${ }^{177}$ and her concerns are not unfounded. This junction between digital techniques and analog film styles, however, shows a need for a more balanced approach to discussing digital cinema. Digital cinema is not in direct opposition to analog film, and both media forms remain deeply dependent on each other.

Examining one specific digital technology and one filmmaking tendency indicates the richness of this material. If cinema studies is to continue evolving with the proliferation of new media, these subtleties need to properly examined, and the constant comparison of digital and analog filmmaking must be downplayed.

\footnotetext{
${ }^{177}$ Anne Friedberg, "The End of Cinema: Multimedia and Technological Change," in The Film Theory Reader: Debates and Arguments, ed. Marc Furstenau (London and New York: Routledge, 2010), 270.
} 


\section{References}

Belton, John. "Digital Cinema: A False Revolution," in The Film Theory Reader: Debates and Arguments, edited by Marc Furstenau, 282-293. London and New York: Routledge, 2010.

--, "Painting by Numbers: The Digital Intermediate." Film Quarterly 61, no. 3 (2008): 58-65.

Bergery, Benjamin. "Silent Splendor." American Cinematographer 92, no. 12 (2011): 68-77.

Bolter, Jay David and Richard Grusin. Remediation: Understanding New Media. Cambridge, Mass.: MIT Press, 1999.

Cook, Pam. Screening the Past: Memory and Nostalgia in Cinema. London \& New York: Routledge, 2004.

Cherchi Usai, Paolo. The Death of Cinema. London: The British Film Institute, 2001.

Drake, Philip. "Mortgaged to Music: New Retro Movies in 1990s Hollywood Cinema," in Memory and Popular Film, edited by Paul Grainge, 183-201. Manchester: Manchester University Press, 2003.

Fisher, Bob. "Black-and-White in Color." American Cinematographer 79, no. 11 (1998): 60-67.

Friedberg, Anne. "The End of Cinema: Multimedia and Technological Change," in The Film Theory Reader: Debates and Arguments, edited by Marc Furstenau, 270-281. London and New York: Routledge, 2010.

Goldman, Michael. “Scorsese's Color Homage.” Millimeter 33, no 1. (2005): 14-26.

Grainge, Paul. "Pleasantville and the Textuality of Media Memory," in Memory and Popular Film, edited by Paul Grainge, 202-219. Manchester: Manchester University Press, 2003.

Gunning, Tom. "The Cinema of Attractions: Early Film, Its Spectator and the Avant-Garde," in Early Cinema: Space, Frame, Narrative, edited by Thomas Elsaesser, 56-62. London: British Film Institute, 1990.

Hope-Jones, Mark. “Through a Child's Eyes.” American Cinematographer 92, no. 12 (2011): 54-67.

Landsberg, Alison. "Prosthetic Memory: The Ethics and Politics of Memory in an Age of Mass Culture," in Memory and Popular Film, edited by Paul Grainge, 144-161. Manchester: Manchester University Press, 2003. 
Le Sueur, Marc. "Theory Number Five: Anatomy of Nostalgia Films: Heritage and Methods." Journal of Popular Film 6, no. 2 (1977): 187-197.

Legato, Robert. “The Aviator: Visual Effects Overview.” Warner Bros. Pictures. Accessed September 14, 2015. http://www.aviatorvfx.com/index.php? $\mathrm{cmd}=$ frontendOverview $\& \mathrm{id}=\mathrm{vfx}$.

Manovich, Lev. The Language of New Media. Cambridge, Mass.: MIT Press, 2001.

Pavlus, John. "High Life.” American Cinematographer 86, no. 1 (2005): 38-53.

Prince, Stephen. Digital Visual Effects in Cinema: The Seduction of Reality. New Brunswick, New Jersey: Rutgers University Press, 2012.

Rodowick, D.N. The Virtual Life of Film. Cambridge, Mass: Harvard University Press, 2007.

Silber, Jon. “A Scandal in Suburbia.” American Cinematographer 83, no. 12 (2002): 54-65.

Sprengler, Christine. Screening Nostalgia: Populuxe Props and Technicolor Aesthetics in Contemporary American Film. New York: Berghan Books, 2009.

Young, Paul. The Cinema Dreams its Rivals: Media Fantasy Films From Radio to Internet. Minneapolis: University of Minnesota Press, 2006. 